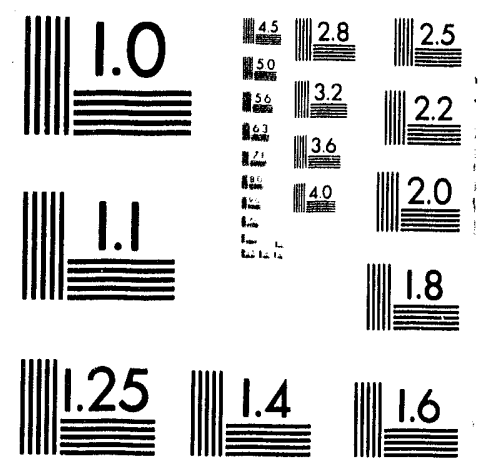



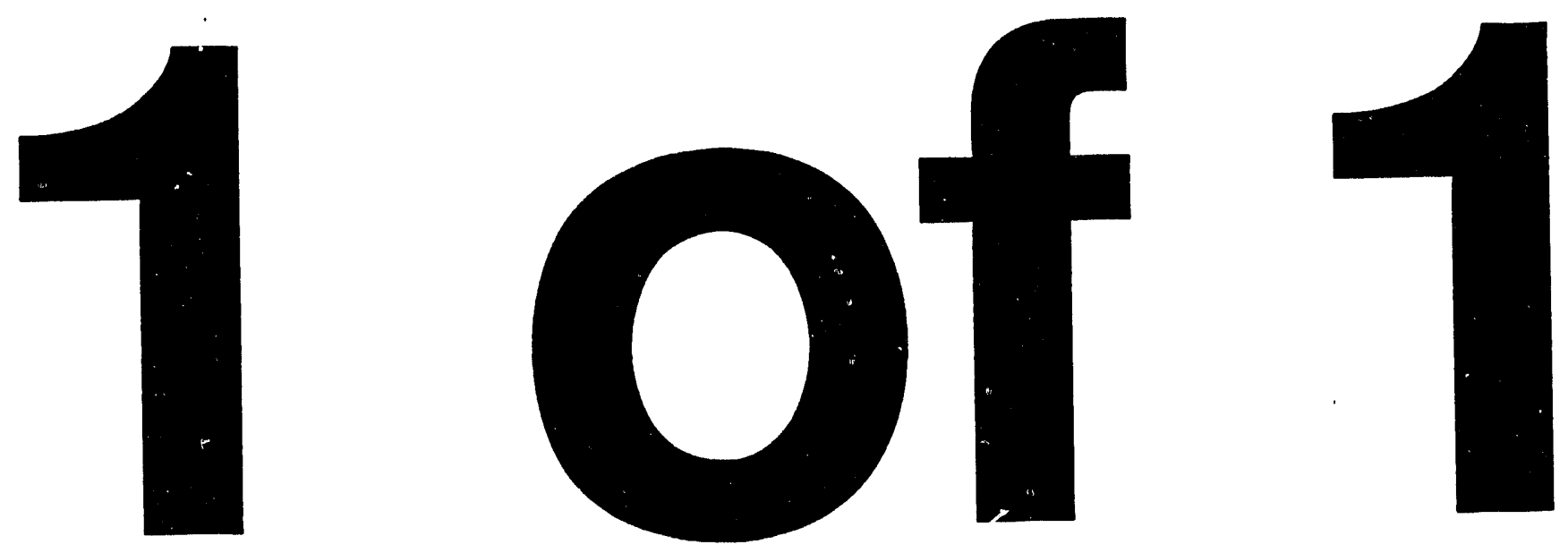


\section{User's Manual for EROSION/MOD1: A Consputer Program for Fluids-Solids Erosion}

\section{Topical Report}

\section{R.W. Lyczkowski}

J.X. Bouillard

S.M. Folga

S.L. Chang

September 1992

Work Performed Under Contract No.: DE-AC21-89MC24193

\section{For}

U.S. Department of Energy

Office of Fossil Energy

Morgantown Energy Technology Center

Morgantown, West Virginia

By

Argonne National Laboratory

Energy Systems Division

Argonne, lllinois 


\section{DISCLAIMER}

This report was prepared as an account of work sponsored by an agency of the United States Government. Neither the United States Government nor any agency thereof, nor any of their employees, makes any warranty, express or implied, or assumes any legal liability or responsibility for the accuracy, completeness, or usefulness of any information, apparatus, product, or process disclosed, or represents that its use would not infringe privately owned rights. Reference herein to any specific commercial product, process, or service by trade name, trademark, manufacturer, or otherwise does not necessarily constitute or imply its endorsement, recommendation, or favoring by the United States Government or any agency thereof. The views and opinions of authors expressed herein do not necessarily state or reflect those of the United States Government or any agency thereof.

This report has been reproduced directly from the best available copy.

Available to DOE and DOE contractors from the Office of Scientific and Technical Information, P.O. Box 62, Oak Ridge, TN 37831; prices available at (615) 576-8401.

Available to the public from the National Technical Information Service, U.S. Department of Commerce, 5285 Port Royal Rd., Springfield, VA 22161; phone orders accepted at (703) 487-4650. 


\title{
User's Manual for EROSION/MOD1: A Computer Program for Fluids-Solids Erosion
}

\author{
Topical Report
}

R.W. Lyczkowski

J.X. Bouillard

S.M. Folga

S.L. Chang

Work Performed Under Contract No.: DE-AC21-89MC24193

For

U.S. Department of Energy

Office of Fossil Energy

Morgantown Energy Technology Center

P.O. Box 880

Morgantown, West Virginia 26507-0880

By

Argonne National Laboratory

Energy Systems Division

9700 South Cass Avenue

Argonne, Illinois 60439-4815

September 1992

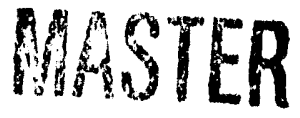

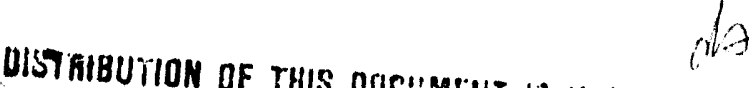




\section{Contents}

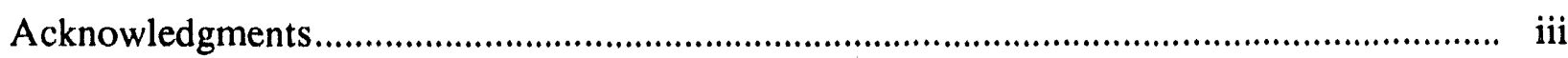

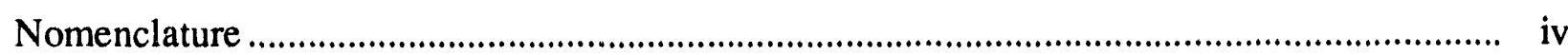

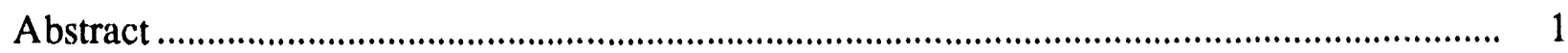

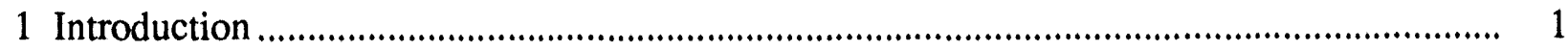

2 Erosion Models .........................................................................................................

2.1 Finnie's Ductile Erosion Model........................................................................... 3

2.2 Neilson and Gilchrist's Combined Ductile and Brittle Erosion Model ...................... 4

2.3 The Monolayer Energy Dissipation Erosion Model ................................................ 7

3 Erosion Model Implementation and Finite-Difference Equations ......................................... 10

3.1 Coupling of Hydrodynamic and Erosion Models ...................................................... 10

3.2 Finite Difference Approximations of the Irreversible Rate of Conversion to Internal Energy ................................................................................ 12

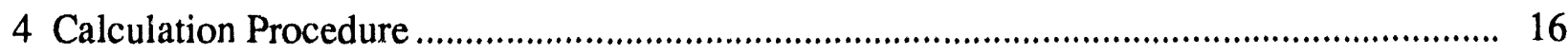

5 Global Structure of the EROSION/MOD1 Computer Program ........................................... 18

5.1 EROSION/MOD1 Subroutines and Their Functions................................................ 18

5.2 Erosion Program Structure Synopsis .................................................................. 18

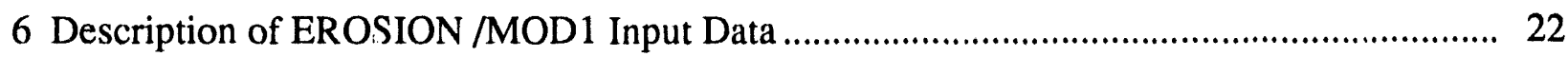

7 Sample Problem for a Fluidized Bed .................................................................................. 26

8 Limitations of Current Erosion Models and Recommendations ................................................ 38

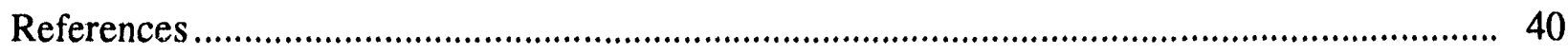

Appendix A: Assessment of Neilson-Gilchrist Erosion Model ............................................... 42

Appendix B: EROSION/MOD1 Principal Fortran Symbols and Definitions ........................... 44

\section{Figures}

1 Neilson and Gilchrist Wear Factors for Aluminum Oxide Particles and Aluminum Plate Target (after, Engel ${ }^{14}$ )

2 Coupling of Hydrodynamic and Erosion Models............................................................ 11

3. Single-Subscript Notation for Cell and Cell-Edge Quantities About Cell (i,j.)................... 13 


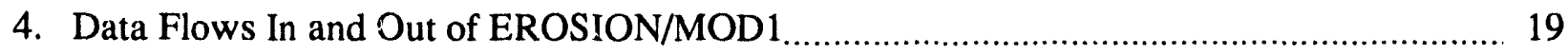

5. EROSION/MOD1 Program Structure and Subroutine Calling Sequences........................... 20

6. Erosion Sample Problem Geometry....................................................................................... 27

7. Summary of Computed Erosion Rates for the $\operatorname{MED}\left(\dot{E}_{\mathrm{EDvCF}}\right)$, Neilson-Gilchrist and Finnie Erosion Models

\section{Tables}

1. Neilson-Gilchrist Erosion Rates for Various Impingement Velocities and Angles for Aluminum Target Eroded by Aluminum Oxide Particles.

2. EROSION/MOD2 Sample Problem Input Data File ......................................................... 28

3. EROSION/MOD2 Sample Problem Output ……………....................................................... 29

4. Key for Energy Dissipation Printed Outputs....................................................................... 37

A.1 Comparison of Erosion Models ........................................................................................ 43 


\section{Acknowledgments}

The support of the Cooperative R\&D Venture Participants listed on the cover page is gratefully acknowledged. Steering Committee participants contributed materially to this document as a result of the FLUFIX EROSION Workshop held at Argonne National Laboratory, October 16-19, 1989. 


\section{Nomenclature}

\begin{tabular}{|c|c|}
\hline c & Compaction modulus \\
\hline $\mathrm{d}_{\mathrm{p}}$ & Particle diameter, $\mathrm{m}$ \\
\hline $\mathrm{dK} E_{\mathrm{S}} / \mathrm{dt}$ & Energy dissipation rate as defined by Eq. $2.13=\mathrm{e}_{\mathrm{vs}}, \mathrm{W} / \mathrm{m}^{3}$ \\
\hline$\dot{\mathrm{E}}$ & Erosion rate, $\mathrm{m} / \mathrm{s}$ \\
\hline$\dot{\mathrm{E}}_{\mathrm{b}}, \dot{\mathrm{E}}_{\mathrm{d}}$ & Brittle and ductile erosion rates, in Neilson-Gilchrist erosion model, Eq. $2.6, \mathrm{~m} / \mathrm{s}$ \\
\hline$\dot{\mathrm{E}}_{\mathrm{F}}$ & Finnie erosion rate given by Eq. $2.1, \mathrm{~m} / \mathrm{s}$ \\
\hline$\dot{E}_{\mathrm{FM}}$ & Maximum erosion rate from Finnie's model given by Eq. $2.5, \mathrm{~m} / \mathrm{s}$ \\
\hline $\mathrm{E}_{\mathrm{p}}, \mathrm{E}_{\mathrm{t}}$ & Young's modulus of particle and target, respectively, $\mathrm{Pa}$ \\
\hline $\mathrm{E}_{\mathrm{r}}$ & Reduced Young's modulus of elasticity given by Eq. 2.10, Pa \\
\hline $\mathrm{E}_{\mathrm{sp}}$ & Specific energy of eroding material (related to hardness), $\mathrm{Pa}$ \\
\hline e & Coefficient of restitution of particle-target collision $=\mathrm{V}_{2} / \mathrm{V}_{1}$ \\
\hline $\begin{array}{l}e_{V} \\
G\end{array}$ & $\begin{array}{l}\text { Rate of kinetic energy dissipation per unit volume, } \mathrm{W} / \mathrm{m}^{3} \\
\text { Solids elastic modulus, } \mathrm{Pa}\end{array}$ \\
\hline $\mathrm{k}_{\mathrm{p}}, \mathrm{k}_{\mathrm{t}}$ & $\begin{array}{l}\text { Elastic constants defined by Eq. } 2.10=\left(1-\gamma_{\mathrm{p}}^{2}\right) /\left(\pi \mathrm{E}_{\mathrm{p}}\right) \text { and }\left(1-\gamma_{\mathrm{t}}^{2}\right) /\left(\pi \mathrm{E}_{\mathrm{t}}\right) \text {, } \\
\text { respectively, } \mathrm{Pa}^{-1}\end{array}$ \\
\hline$\underline{g}$ & Acceleration due to gravity, $\mathrm{m} / \mathrm{s}^{2}$ \\
\hline$\overline{\mathrm{I}}$ & Unity tensor \\
\hline$\dot{\mathrm{m}}_{\mathrm{s}}$ & Mass flux of solids $=\varepsilon_{\mathrm{s}} \rho_{\mathrm{s}}\left|\overrightarrow{\mathrm{v}}_{\mathrm{s}}\right|, \mathrm{kg} /\left(\mathrm{m}^{2} \cdot \mathrm{s}\right)$ \\
\hline $\mathrm{n}$ & Empirical constant in Eq. 2.6 \\
\hline $\mathrm{P}$ & Pressure, $\mathrm{Pa}$ \\
\hline$P_{t}$ & Eroding flow stress or hardness of target, $\mathrm{Pa}$ \\
\hline $\mathrm{r}$ & Radial coordinate, $\mathrm{m}$ \\
\hline $\mathrm{t}$ & Time, $\mathrm{s}$ \\
\hline UED & Kinetic energy dissipation per unit area, Eq. $2.14 \mathrm{a}, \mathrm{W} / \mathrm{m}^{2}$ \\
\hline $\mathrm{U}_{\mathrm{g}}, \mathrm{U}_{\mathrm{S}}$ & Gas and solid phase velocities in the $x$ direction, respectively, $\mathrm{m} / \mathrm{s}$ \\
\hline UEDV & Kinetic energy dissipation rate per unit area, Eq. $2.14 \mathrm{~b}, \mathrm{~W} / \mathrm{m}^{2}$ \\
\hline UEDvCF & Kinetic energy dissipation rate per unit area, Eq. $214 c, W / \mathrm{m}^{2}$ \\
\hline UEDVREL & Kinetic energy dissipation rate per unit area, Eq. $2.14 \mathrm{~d}, \mathrm{~W} / \mathrm{m}^{2}$ \\
\hline V & Velocity, $\mathrm{m} / \mathrm{s}$ \\
\hline$v_{g}, v_{S}$ & Gas and solid phase velocities in the $y$ direction, respectively, $\mathrm{m} / \mathrm{s}$ \\
\hline Vel & Threshold velocity defined by Eq. $2.9 \mathrm{~m} / \mathrm{s}$ \\
\hline $\mathrm{V}_{1}, \mathrm{~V}_{2}$ & Approach and rebound particle velocities, respectively, $\mathrm{m} / \mathrm{s}$ \\
\hline$\vec{v}$ & Velocity vector, $\mathrm{m} / \mathrm{s}$ \\
\hline$|\vec{v}|$ & Magnitude of velocity vector, $\mathrm{m} / \mathrm{s}$ \\
\hline$x$ & Lateral coordinate, $\mathrm{m}$ \\
\hline & Axial coordinate, $\mathrm{m}$ \\
\hline & Axial coordinate, $m$ \\
\hline
\end{tabular}

\section{Greek Letters}

$\alpha \quad$ Impingement angle, degrees

$\alpha_{0} \quad$ Transition impingement angle, degrees 
$\overline{\bar{\beta}}_{\mathrm{A}}, \overline{\bar{\beta}}_{\mathrm{B}}, \quad$ Fluid-particle friction tensors for hydrodynamic models $\mathrm{A}$ and $\mathrm{B}$, respectively, $\left(=\beta_{\mathrm{A}} \overline{\overline{\mathrm{I}}}, \beta_{\mathrm{B}} \overline{\overline{\mathrm{I}}}\right), \mathrm{kg} /\left(\mathrm{m}^{3} \cdot \mathrm{s}\right)$

$\beta_{A}, \beta_{B} \quad$ Fluid-particle interphase drag, $\mathrm{kg} /\left(\mathrm{m}^{3} . \mathrm{s}\right)$

$\gamma_{p}, \gamma_{t} \quad$ Poisson's ratio of particle and target, respectively

$\delta \mathrm{x}, \Delta \mathrm{x}, \mathrm{DX}$ Cell size in Cartesian coordinates $(\mathrm{x}, \mathrm{y}), \mathrm{m}$

$\delta y, \Delta y, D Y$ Cell size in Cartesian coordinates $(x, y), m$

$\delta \mathrm{r}, \mathrm{DR} \quad$ Cell size in cylindrical coordinates $(\mathrm{r}, \mathrm{z}), \mathrm{m}$

$\delta \mathrm{z}, \mathrm{DZ} \quad$ Cell size in cylindrical coordinates $(\mathrm{r}, \mathrm{z}), \mathrm{m}$

$\varepsilon \quad$ Fluid-phase volume fraction (porosity)

$\varepsilon_{s} \quad$ Solids-phase volume fraction $=(1-\varepsilon)$

$\varepsilon^{*} \quad$ Compaction gas volume fraction

$\overline{\bar{\tau}}_{\mathrm{kv}} \quad$ Viscous stress, $\mathrm{Pa}$

$\mu_{\mathrm{f}} \quad$ Fluid viscosity, Pa.s

$\xi_{\mathrm{b}} \quad$ Material-úependent brittle (deformation) wear factor, $\mathrm{Pa}$

$\rho$ Density, $\mathrm{kg} / \mathrm{m}^{3}$

$\rho_{\mathrm{s}}, \rho_{\mathrm{f}} \quad$ Solids- and fluid-phase microscopic densities, respectively, $\mathrm{kg} / \mathrm{m}^{3}$

$\rho_{\mathrm{s}}^{\prime}, \rho_{\mathrm{f}}^{\prime} \quad$ Solids-and fluid-phase macroscopic (partial) densities, respectively, $\rho_{\mathrm{s}}^{\prime}=\rho_{\mathrm{s}}(1-\varepsilon)$ and $\rho_{\mathrm{f}}^{\prime}=\rho_{\mathrm{f}} \varepsilon, \mathrm{kg} / \mathrm{m}^{3}$

$\rho_{\mathrm{p}} \quad$ Particle density, $\mathrm{kg} / \mathrm{m}^{3}$

$\sigma_{y} \quad$ Elastic load limit (yield tensile strength), $\mathrm{Pa}$

$\tau \quad$ Yield shear stress, $\mathrm{Pa}$

$\overline{\bar{\tau}}_{\mathrm{sv}} \quad$ Solids viscous stress, $\mathrm{Pa}$

$\phi_{c} \quad$ Material-dependent ductile (cutting) wear factor, $\mathrm{Pa}$

$\phi_{\mathrm{s}} \quad$ Sphericity of solid particles (shape factor), $0<\phi_{\mathrm{s}} \leq 1$

\section{Superscripts}

\begin{tabular}{ll}
$\rightarrow$ & Denotes time rate of change \\
$\vec{n}$ & Denotes a vector quantity \\
$\mathrm{n}, \mathrm{n}+1$ & Denotes a tensor quantity \\
\hline
\end{tabular}

\section{Indexes and Subscripts}

$\begin{array}{ll}\mathrm{b} & \text { Brittle } \\ \mathrm{d} & \text { Ductile } \\ \mathrm{f} & \text { Fluid phase } \\ \mathrm{i} \text { or I } & \text { Cell index in } \mathrm{x} \text { or } \mathrm{r} \text { direction } \\ \mathrm{j} \text { or J } & \text { Cell index in y or } \mathrm{z} \text { direction } \\ \mathrm{p} & \text { Particle } \\ \mathrm{s} & \text { Solids phase } \\ \mathrm{t} & \text { Target } \\ \mathrm{x} & \text { x-direction coordinate } \\ \text { y } & \text { y-direction coordinate } \\ \mathrm{z} & \text { z-direction coordinate }\end{array}$




\section{Operators}

$\frac{d}{d^{s}} \quad$ Total derivative following the solids $=\frac{\partial}{\partial t}+\vec{v}_{s} \cdot \nabla$

$\nabla$. Divergence

$\nabla \quad$ Gradient 


\title{
User's Manual for EROSION/MOD1: A Computer Program for Fluid-Solids Erosion
}

\author{
by \\ R.W. Lyczkowski, J.X. Bouillard, S.M. Folga, and S.L. Chang
}

\begin{abstract}
This report describes EROSION/MOD1, a computer program that was developed as a two-dimensional analytical tool for the general analysis of erosion in fluid-solids systems and the specific analysis of erosion in bubbling fluidizedbed combustors. Contained herein are implementations of Finnie's impaction erosion model, Neilson and Gilchrist's combined ductile and brittle erosion model, and several forms of the monolayer energy dissipation erosion model. These models and their implementations are described briefly. The global structure of EROSION/MOD1 that contains these models is also discussed. The input data for EROSION/MOD1 are given, and a sample problem for a fluidized bed is described. The hydrodynamic input data are assumed to come from the output of FLUFIX/MOD2.
\end{abstract}

\section{Introduction}

Excellent heat transfer from gas fluidized beds to the surfaces of immersed heat exchanger tubes is one of the most attractive features of bubbling atmospheric and pressurized fluidized-bed combustors (FBCs). Unfortunately, erosion (alternatively referred to as metal wastage) of these tube banks caused by vigorous solids motion, sometimes plagues their operation and must be mitigated to achieve reasonable lifetimes $(\sim 100,000 \mathrm{~h})$ for commercial FBCs. Data recorded at the Grimethorpe cold model facility demonstrated that the tube metal loss rate could be reduced by more than one order of magnitude ${ }^{1}$ to complete FBC experiments without catastrophic tube failures.

Earlier studies have indicated that one of the determining factors affecting the erosion of ductile and brittle materials is the velocity of the particles impinging upon the target. For flat surfaces impacted by single particles, the erosion rate has been shown $n^{2,3}$ to be proportional to the particle's velocity raised to the power 2 to 2.5 .

More recently, simplified models for FBC erosion have been developed that attempt to relate the solids velocity to easily measurable quantities such as the bubble diameter, the bubble velocity, the bed porosity, and the fluidizing velocity. ${ }^{4-7}$ Gansley and O'Brien 6 developed an analytical erosion expression by utilizing Davidson's classical bubble model, Finnie's singleparticle impaction erosion model, and an empirical expression for the bubble diameter. Wood and Woodford ${ }^{5}$ treated erosion simply as the result of metal fatigue rather than metal cutting. Yates ${ }^{4}$ developed a simplified erosion model that, like Argonne National Laboratory's (ANL's) monolayer energy dissipation (MED) erosion model, 7 is based on the premise that the erosion rate is proportional to the kinetic energy of the particles. Yate's erosion model predicts that this kinetic energy would be proportional to the fourth power of the bubble diameter. This functional dependency assumes that the solids move at the bubble rise velocity. 
The computer program EROSION/MOD1 was developed as part of a coordinated effort by industry, government, and universities - known as the Cooperative R\&D Venture, "Erosion of FBC Heat Transfer Tubes" - to better understand metal wastage in FBCs. This computer program utilizes detailed solids hydrodynamic as input calculations from the FLUFIX ${ }^{8}$ computer program. Three erosion models are included in the EROSION computer program: (1) Finnie's erosion model, ${ }^{2}$ (2) Neilson and Gilchrist's, ${ }^{3}$ erosion model, and (3) ANL's MED erosion model ${ }^{7}$ developed during the course of the Cooperative R\&D Venture.

Two reports that should be considered integral companions to this EROSION/MOD1 User's Manual are the FLUFIX/MOD1 User's Manual, 8 which has been updated to become the FLUFIX/MOD2 User's Manual, and a review of erosion models that also served as a preliminary erosion computer program description. ${ }^{9}$ One is also referred to Bouillard's ${ }^{10}$ Chapter 6 and Appendix E. The availability of these resources makes it possible to keep the background and theory in this report to a minimum.

The methodologies employed in the EROSION/MOD1 computer program are not limited to erosion of FBC components, and may be used to predict erosion in any kind of solids processing device. These devices include circulating fluidized beds, fluid catalytic crackers (FCCs), and pneumatic and slurry transport pipelines. 


\section{Erosion Models}

This section summarizes the erosion models contained in the EROSION/MOD1 computer program. An evaluation of the available literature is contained in Lyczkowski et al. ${ }^{9}$

\subsection{Finnie's Ductile Erosion Model}

Finnie's erosion model ${ }^{2}$ is a single-particle impaction cutting model. The particle approaching the surface at an angle $\alpha$ to its normal impingement angle removes the surface material in a manner similar to a machine cutting tool. The particle is assumed to be much harder than the surface, and so it does not break up. The surface material is assumed to deform plastically during the cutting process; hence, the surface material is considered ductile.

To apply Finnie's original erosion model to computer erosion rates, not for a singleparticle impact, but rather for a continuum flux of particles hitting the surface as in a dense fluidized bed, the model was extended (Lyczkowski et al. ${ }^{9}$ ). They introduced the local solids, loading $\varepsilon_{\mathbf{s}}$ into the final expression of the erosion rate, $\dot{\mathrm{E}}_{\mathrm{F}}$

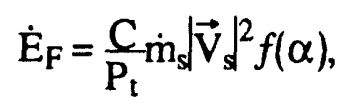

where $\dot{\mathrm{m}}_{\mathrm{s}}$ is the flux of particles hitting the surface; that is,

$$
\dot{\mathrm{m}}_{\mathrm{s}}=\rho_{\mathrm{s}} \varepsilon_{\mathrm{s}} \mid \overrightarrow{\mathrm{V}}_{\mathrm{s}}
$$

Utilizing the parameters in Finnie's erosion model, the factor, $C$, in Eq. $2.1=1 / 8 . P_{t}$ is the target (Vicker's) hardness, $\mid \vec{V}_{\mathrm{d}}$ is the solids velocity magnitude, and $f(\alpha)$ is given by

$$
f(\alpha)= \begin{cases}\sin (2 \alpha)-3 \sin ^{2}(\alpha) & \alpha \leq 18.43^{\circ} \\ \cos ^{2}(\alpha) / 3 & \alpha>18.43^{\circ}\end{cases}
$$

Below $18.43^{\circ}$, the surface is cut until the particle leaves the surface; above $18.43^{\circ}$, cutting ceases before the particle leaves the surface. The transition angle given in Eq. 2.3 is close to the angle of maximum erosion, $\alpha_{\max }$, given by

$$
\alpha_{\max }=\frac{1}{2} \tan ^{-1}(2 / 3)=16.85^{\circ}
$$

The disagreement with Finnie's model as used by Pourahmadi and Humphrey ${ }^{11}$ was discussed by Lyczkowski et al. ${ }^{9}$

At $18.43^{\circ}$, Finnie's model yields an erosion rate for ductile target materials given by

$$
\dot{\mathrm{E}}_{\mathrm{FM}}=0.075 \frac{\dot{\mathrm{m}}{ }_{\mathrm{d}} \overrightarrow{\mathrm{V}}_{\mathrm{s}}{ }^{2}}{2 \mathrm{P}_{\mathrm{t}}}
$$

which is, in effect, the maximum value. Equation 2.5 predicts that only $7.5 \%$ of the particle's kinetic energy goes into erosion for a given target hardness, $\mathrm{P}_{\mathrm{t}}$. 
Erosion models in general, and Finnie's erosion model in particular, cannot be used to calculate absolute erosion rates a priori. The reason for this is that assumptions need to be made concerning the most appropriate properties in the erosion models (e.g., yield strength, Young's modulus, Vickers hardness, etc.), as well as the submodels and their parameters. Finnie's erosion model can be used, together with estimates of target material flow stress, $P_{t}$ (or Vicker's hardness), to back out a value for parameter $C$ to match the data. On the other hand, if a value for $C$ is assumed, then the value of the flow stress or hardness appropriate for erosion is backed out of the data.

The angular dependence of the erosion rate predicted by using Finnie's model is quite good up to $45^{\circ}$. Above $45^{\circ}$, Finnie's model underpredicts the erosion rate; at $90^{\circ}$, it predicts no erosion at all, whereas the analyzed data clearly indicate that this prediction is not correct. ${ }^{2}$ The model described in the next section overcomes one of these shortcomings.

\subsection{Neilson and Gilchrist's Combined Ductile and Brittle Erosion Model}

The Neilson-Gilchrist (NG) erosion $\operatorname{model}^{3}$ is included in the EROSION/MOD1 computer program because it has the capability of computing erosion at a $90^{\circ}$ angle of particle incidence relative to the eroding surface. It also has normal and parallel velocity threshold components below which erosion does not take place. However, in place of a single value for hardness, two material properties are needed to characterize cutting and deformation energy absorption.

The NG erosion model ${ }^{3}$ is a simplification of Bitter's earlier model. ${ }^{12,13}$ It consists of the sum of a ductile erosion rate, $\dot{\mathrm{E}}_{\mathrm{d}}$, and a brittle erosion rate, $\dot{\mathrm{E}}_{\mathrm{b}}$. The resulting wear expression, as extended by Lyczkowski et al. ${ }^{9}$, is given by

$\dot{\mathrm{E}}_{\mathrm{NG}}=\dot{\mathrm{E}}_{\mathrm{d}}+\dot{\mathrm{E}}_{\mathrm{b}}= \begin{cases}\frac{\dot{\mathrm{m}}_{\mathrm{s}}\left|\overrightarrow{\mathrm{V}}_{\mathrm{s}}\right|^{2} \cos ^{2}(\alpha) \sin (\alpha)}{2 \phi_{\mathrm{c}}}+\frac{\dot{\mathrm{m}}_{\mathrm{s}}\left[\left|\overrightarrow{\mathrm{V}}_{\mathrm{s}}\right| \sin (\alpha)-\mathrm{V}_{\mathrm{el}}\right]^{2}}{2 \xi_{\mathrm{b}}} & \alpha \leq \alpha_{0} \\ \frac{\dot{\mathrm{m}}_{\mathrm{s}}\left|\overrightarrow{\mathrm{V}}_{\mathrm{s}}\right|^{2} \cos ^{2}(\alpha)}{2 \phi_{\mathrm{c}}}+\frac{\dot{\mathrm{m}}_{\mathrm{s}}\left[\left|\overrightarrow{\mathrm{V}}_{\mathrm{s}}\right| \sin (\alpha)-\mathrm{V}_{\mathrm{el}}\right]^{2}}{2 \xi_{\mathrm{b}}} & \alpha>\alpha_{0}\end{cases}$

with the provision that $\dot{\mathrm{E}}_{\mathrm{b}}=0$ when $\left|\overrightarrow{\mathrm{V}}_{\mathrm{s}}\right| \sin (\alpha)<\mathrm{V}_{\mathrm{el}}$ and $\alpha_{0}=\pi / 2 \mathrm{n}$, where $\mathrm{n}$ is an empirical constant. This model was extended in the same way as Finnie's model (i.e., by introducing the mass flux of particles).

In addition, the ductile (cutting) and brittle (deformation) wear factors, $\phi_{\mathrm{c}}$ and $\xi_{\mathrm{b}}$, published by Neilson and Gilchrist ${ }^{3}$ for $210 \mu \mathrm{m}$ aluminum oxide particles and aluminum plate target, were curve fit in dimensionless form, shown in Figure 1 (taken from Engel ${ }^{14}$ ) in the range $(100 \mathrm{~m} / \mathrm{s} \leq \mathrm{V} \leq 200 \mathrm{~m} / \mathrm{s})$, as

$$
\phi_{c} /\left(\tau / \rho_{s}\right)=54.21[1+\exp (0.06793(115.27-V))]
$$

and

$$
\xi_{\mathrm{b}} /\left(\sigma_{\mathrm{y}} / \rho_{\mathrm{s}}\right)=82.52[1+\exp (0.07942(110.13-\mathrm{V}))]
$$



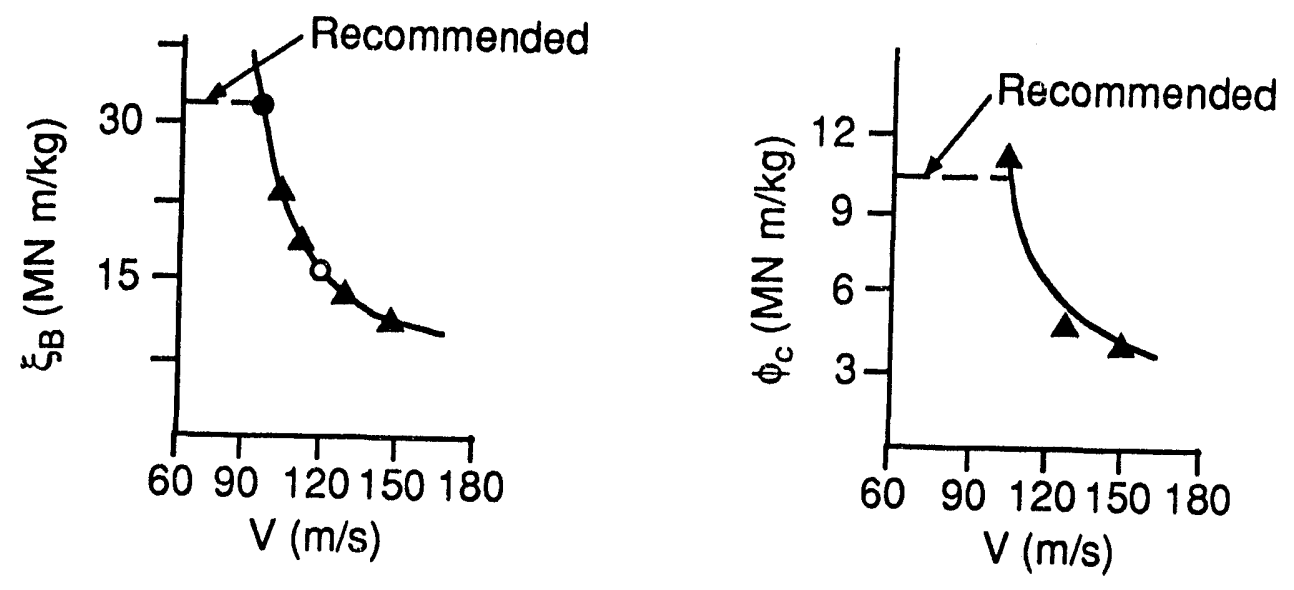

Size of abrasive particles: ○ $100 \mu \mathrm{m}$

$\triangle 210 \mu \mathrm{m}$

- $297 \mu \mathrm{m}$

Figure 1 Neilson and Gilchrist Wear Factors for Aluminum Oxide Particles and Aluminum Plate Target (after Engel ${ }^{14)}$. 
where $\tau$ is the yield shear stress and $\sigma_{y}$ is the yield tensile stress (plastic load limit) of the aluminum target $\left(\tau=0.6 \sigma_{y}\right.$ and $\left.\sigma_{y}=414 \mathrm{MPa}\right) .14$ Since the ductile and brittle wear factors decrease with increasing particle impingement velocity, this may indicate some sort of dynamic softening of the target material.

Since data to determine the wear factors $\phi_{c}$ and $\xi_{b}$ for conditions existing in FBCs are lacking, it is recommended that the values of these two factors evaluated at the lower bound of the experimental velocity data $(107.8 \mathrm{~m} / \mathrm{s})$ be used as shown in Figure 1 . If this is done, erosion rates are in rough agreement with the MED erosion model, as shown in Appendix A N.B.: At present, only wear factors for aluminum target material are in the EROSION/MOD1 computer program.

With $\alpha_{0}$ chosen to be $18.43^{\circ}$, the same as in Finnie's erosion model described in Section $2.1, n$ becomes 4.89 from the relationship $\alpha_{0}=\pi /(2 n)$. The wear factors calculated from the above empirical formula are in excellent agreemert with the experimental data ${ }^{3}$ in a velocity range from 100 to $150 \mathrm{~m} / \mathrm{s}$.

Neilson and Gilchrist ${ }^{3}$ did not report the threshold velocity normal to the target, $\mathrm{V}_{\mathrm{el}}$, in their erosion analysis of aluminum plates because they stated it is usually small relative to the particle velocity. It can, however, be estimated from the theoretical expression from the Hertz contact theory given as ${ }^{14}$

$$
\mathrm{V}_{\mathrm{el}}=15.4 \sigma_{\mathrm{y}}^{5 / 2} \rho_{\mathrm{p}}^{-1 / 2} \mathrm{E}_{\mathrm{r}}^{-2}
$$

where $\sigma_{y}$ is the plastic load limit, $\rho_{p}$ is the particle density, and $E_{r}$ is the reduced Young's modulus of elasticity. The value of $E_{r}$ is given by

$$
\mathrm{E}_{\mathrm{r}}=\frac{1}{\left.\left[\left(1-\gamma_{\mathrm{p}}^{2}\right)\right] /\left[\pi \mathrm{E}_{\mathrm{p}}\right)\right]+\left[\left(1-\gamma_{\mathrm{t}}^{2}\right] /\left[\pi \mathrm{E}_{\mathrm{t}}\right]\right.} \equiv \frac{1}{\left(\mathrm{k}_{\mathrm{p}}+\mathrm{k}_{\mathrm{l}}\right)}
$$

where $\gamma_{p}$ and $\gamma_{t}$ are the Poisson's ratios and $E_{p}$ and $E_{t}$ are the Young's moduli of elasticity for the particle and target, respectively.

Using the values ${ }^{15}$

$$
\begin{aligned}
& \sigma_{y}=0.414 \times 10^{9} \mathrm{~Pa}, \\
& \rho_{p}=0.244 \times 10^{4} \mathrm{~kg} / \mathrm{m}^{3}, \\
& \gamma_{p}=0.1 \text { (estimated), } \\
& E_{p}=0.55 \times 10^{11} \mathrm{~Pa} \text { (estimated), }
\end{aligned}
$$

and

$$
\mathrm{E}_{\mathrm{t}}=0.20 \times 10^{12} \mathrm{~Pa} \text {, }
$$


a reduced Young's modulus, $\mathrm{E}_{\mathrm{r}}=0.14 \times 10^{12} \mathrm{~Pa}$, and a threshold velocity, $\mathrm{V}_{\mathrm{el}}=0.056 \mathrm{~m} / \mathrm{s}$, are computed. The threshold velocity, $\mathrm{Vel}$, can also be determined from particle rebound data by using the following relationship: 12

$$
\mathrm{V}_{2}=\sqrt{2 \mathrm{~V}_{1} \mathrm{~V}_{\mathrm{el}}-\mathrm{V}_{\mathrm{el}}^{2}}
$$

where $V_{1}$ and $V_{2}$ are the velocities before and after collision, respectively.

An assessment of the NG erosion model was carried out using solids velocities typical of those in fluidized beds. The results are summarized in Table 1. The results indicate that the erosion rate is strongly dependent on the solids velocity. The maximum erosion rate at a specified velocity occurs at an angle slightly below $\alpha_{0}=18.43^{\circ}$. The angle at which maximum erosion occurs, $\alpha_{\max }$, is obtained by setting $\mathrm{dE} / \mathrm{d} \alpha=0$ from Eq. 2.6b. Table 1 shows that the erosion rate is roughly proportional to the velocity raised to the power 3.5 . In other words, the particle velocity is a dominant parameter in determining the erosion rate for the NG model.

TABLE 1 Neilson-Gilchrist Erosion Rates for Various Impingement Velocities and Angles for Aluminum Target Eroded by Aluminum Oxide Particles

\begin{tabular}{cc|cc}
\hline & $\alpha=90^{\circ}$ & \multicolumn{2}{c}{$V=1 \mathrm{~m} / \mathrm{s}$} \\
\hline$V(\mathrm{~m} / \mathrm{s})$ & $\begin{array}{c}\text { Erosion Rate } \\
(\mathrm{mm} / 1000 \mathrm{~h})\end{array}$ & $\begin{array}{c}\text { Impinging Angle, } \alpha \\
(\mathrm{deg})\end{array}$ & $\begin{array}{c}\text { Erosion Rate } \\
(\mathrm{mm} / 1000 \mathrm{~h})\end{array}$ \\
\hline 1.00 & $1.107 \times 10^{-2}$ & 0.00 & 0.0 \\
0.90 & $7.903 \times 10^{-3}$ & 10.00 & $6.451 \times 10^{-2}$ \\
0.80 & $5.415 \times 10^{-3}$ & 20.00 & $1.090 \times 10^{-1}$ \\
0.70 & $3.522 \times 10^{-3}$ & 30.00 & $9.419 \times 10^{-2}$ \\
0.60 & $2.137 \times 10^{-3}$ & 40.00 & $7.606 \times 10^{-2}$ \\
0.50 & $1.177 \times 10^{-3}$ & 50.00 & $5.682 \times 10^{-2}$ \\
0.40 & $5.606 \times 10^{-4}$ & 60.00 & $3.874 \times 10^{-2}$ \\
0.30 & $2.099 \times 10^{-4}$ & 70.00 & $2.401 \times 10^{-2}$ \\
0.20 & $4.834 \times 10^{-5}$ & 80.00 & $1,441 \times 10^{-2}$ \\
0.10 & $2.238 \times 10^{-6}$ & 90.00 & $1.107 \times 10^{-2}$ \\
0.00 & 0.0 & &
\end{tabular}

\subsection{The Monolayer Energy Dissipation Erosion Model}

The MED erosion model is a significant extension of the so-called power dissipation erosion model for low-angle erosion caused by slurries, which was proposed by Ushimaru et al. 16 Lyczkowski et al. ${ }^{9}$ discussed motivations of the power dissipation erosion model and extended it by deriving an early form of the MED erosion model.

A review of the most recently developed comprehensive MED erosion models was given by Bouillard et al. 7 These models are based on the premise that the mechanical energy of the solids is irreversibly dissipated in the neighborhood of stationary surfaces by three competitive mechanisms:

1. Heat transfer between the gas and the solids particles, between the gas and the tube surfaces, and between the solids and the tube surfaces; 


\section{Erosion of obstacles; and}

3. Attrition of solids particles.

Thus, the rate of energy dissipated in erosion represents only a fraction of the total power dissipation (which is related to the total entropy produstion).

The presently recommended form of the MED erosion model, which is essentially the one derived by Bouillard et al. ${ }^{7}$, as refined by Bouillard and Lyczkowski, 17 is given by

$$
\dot{\mathrm{E}}_{\mathrm{MED}}=\frac{\left(1-\mathrm{e}^{2}\right)}{\mathrm{P}_{\mathrm{t}}}\left[\left(\varepsilon_{\mathrm{s}} \overline{\bar{\tau}}_{\mathrm{sv}}\right): \nabla \overrightarrow{\mathrm{v}}_{\mathrm{s}}+\left(\overrightarrow{\mathrm{v}}_{\mathrm{s}} \cdot \overline{\bar{\beta}}_{\mathrm{B}} \cdot \overrightarrow{\mathrm{v}}_{\mathrm{s}}\right) / 2\right] \mathrm{d}_{\mathrm{p}}
$$

The factor $\left(1-\mathrm{e}^{2}\right)$, where $\mathrm{e}$ is the target-particle coefficient of restitution, is given by $\mathrm{V}_{\mathrm{s} 1}^{2}-\mathrm{V}_{\mathrm{s} 2}^{2}=\left(1-\mathrm{e}^{2}\right) \mathrm{V}_{\mathrm{s} 1}^{2}$. The subscripts 1 and 2 denote solids velocities before and after collision with the target surface. Typically, $\mathrm{e}^{2} \sim 0.9,18$ and this is the default value used in the EROSION/MOD1 code.

The expression for the solids kinetic energy dissipation rate per unit volume was derived by Lyczkowski et al. ${ }^{9}$ For reference, it is quoted as follows:

$$
\begin{aligned}
& e_{v s}=-\frac{d K E_{s}}{d t} \\
& =\left(\varepsilon_{s} \overline{\bar{\tau}}_{s v}\right): \nabla \vec{v}_{s}=-\left\{\varepsilon_{s} \rho_{s} \vec{v}_{s} \cdot \frac{\partial \vec{v}_{s}}{\partial t}+\varepsilon_{s} \rho_{s} \vec{v}_{s} \cdot\left(\vec{v}_{s} \cdot \nabla \vec{v}_{s}\right)\right. \\
& 1 \\
& +\left(\varepsilon_{s} \vec{v}_{s}\right) \cdot \nabla P+\vec{v}_{s} \cdot \bar{\beta}_{A} \cdot\left(\vec{v}_{s}-\vec{v}_{f}\right)-G\left(\varepsilon_{s}\right) \vec{v}_{s} \cdot \overline{\bar{I}} \cdot \nabla \varepsilon \\
& \quad \begin{array}{c}
3 \\
\left.-\varepsilon_{s} \rho_{s} \vec{v}_{s} \cdot \vec{g}-\nabla \cdot\left[\left(\varepsilon_{s} \bar{\tau}_{s v}\right) \cdot \vec{v}_{s}\right]\right\} \\
6
\end{array}
\end{aligned}
$$

The six terms (1-6) in braces are contained in the prototype EROSION code described by Lyczkowski et al. ${ }^{9}$ The seventh term $\nabla \cdot\left[\left(\varepsilon_{s} \vec{\tau}_{\mathrm{sv}}\right): \nabla \overrightarrow{\mathrm{v}}_{\mathrm{s}}\right]$ contained in Eq. 2.13 , as well as other forms of the kinetic energy dissipation per unit volume, as discussed by Bouillard et al., 7 are used in the EROSION code. Hence, there are four forms of the kinetic energy dissipation rate per unit volume in EROSION/MOD1. They are given by

$$
\begin{aligned}
& \mathrm{U}_{\mathrm{ED}}=\left(\text { Terms } 1-7 \text { in Eq. 2.13) } \mathrm{d}_{\mathrm{p}}\right. \\
& \mathrm{U}_{\mathrm{EDv}}=\left[\left(\varepsilon_{\mathrm{s}} \overline{\bar{\tau}}_{\mathrm{sv}}\right): \nabla \overrightarrow{\mathrm{v}}_{\mathrm{s}}\right] \mathrm{d}_{\mathrm{p}} \\
& \mathrm{U}_{\mathrm{EDvCF}}=\left[\left(\varepsilon_{\mathrm{s}} \overline{\bar{\tau}}_{\mathrm{sv}}\right): \nabla \overrightarrow{\mathrm{v}}_{\mathrm{s}}+\overline{\bar{\beta}}_{\mathrm{B}} \overrightarrow{\mathrm{v}}_{\mathrm{s}}^{2} / 2\right] \mathrm{d}_{\mathrm{p}}
\end{aligned}
$$




$$
U_{\text {EDvREL }}=\left[\left(\varepsilon_{\mathrm{s}} \overline{\bar{\tau}}_{\mathrm{sv}}\right): \nabla \overrightarrow{\mathrm{v}}_{\mathrm{s}}+\varepsilon_{\mathrm{s}} \overline{\bar{\beta}}_{\mathrm{B}}\left(\overrightarrow{\mathrm{v}}_{\mathrm{f}}-\overrightarrow{\mathrm{v}}_{\mathrm{s}}\right)\right] \mathrm{d}_{\mathrm{p}}
$$

To obtain the corresponding erosion rate, Eqs. 2-14a through $2.14 \mathrm{~d}$ are used successfully in the brackets in the MED erosion model given by Eq. 2.12 to obtain

$$
\begin{aligned}
& \dot{E}_{E D}=\left(1-e^{2}\right) U_{E D} d_{p} / P_{t} \\
& \dot{E}_{E D v}=\left(1-e^{2}\right) U_{E D v} d_{p} / P_{\mathfrak{t}} \\
& \dot{E}_{E D v C F}=\left(1-e^{2}\right) U_{E D v R E L} d_{p} / P_{t}
\end{aligned}
$$

and

$$
\dot{E}_{\text {EDvREL }}=\left(1-e^{2}\right) U_{\text {EDvREL }} d_{p} / P_{\mathfrak{t}}
$$

Bouillard and Lyczkowski 17 provides a discussion of a simplified MED erosion model, based upon Eq. 2.12, that uses simplified solids rheology and hydrodynamics. 


\section{Erosion Model Implementation and Finite-Difference Equations}

The application of algebraic and differential erosion models to fluid-solids systems is described in this section, as well as the finite difference equations for the monolayer energy dissipation models.

\subsection{Coupling of Hydrodynamic and Erosion Models}

A typical FLUFIX ${ }^{8}$ computational cell next to a tube surface is shown in Figure 2 . If the tube is round, it must be approximated with a "staircase" approximation, as indicated because Cartesian coordinates are used. The normal velocities of the gas and solids phases are set equal to zero on all the approximate tube surfaces. The gas tangential velocities are set to zero and solids tangential velocities are either set to zero or partial slip. ${ }^{19}$ If the obstacle is rectangular and aligned along the coordinate direction, no approximation is necessary.

For the NG and Finnie algebraic erosion models described in Sections 2.1 and 2.2, the solid phase velocities in each direction are resolved at the cell center and the magnitude of the velocity is obtained. The angle of the resolved velocity vector at the cell center with respect to each horizontal and vertical approximate tube surface is then obtained. A further discussion of the angle determination is found in Section 6. The porosity is known at the cell center, so the mass flux of the solid is computed from the magnitude of the velocity resolved at the cell center and the porosity times the density (which is constant). Given the tube material hardness, $\mathrm{E}_{\mathrm{sp}}$, or flow pressure, $\mathrm{P}_{t}$, and some estimate for the restitution coefficient, $e$, the erosion rate is obtained. This is done by using as inputs the transient FLUFIX outputs saved from the solution of the hydrodynamic equations.

The MED erosion models require derivatives of the solids phase velocities to compute the energy dissipation rates at the cell centers around the obstacle. In addition, the gas and solids phase velocities are required to compute the energy dissipation rates caused by drag, and gradients of pressure are needed to evaluate the pressure work terms. A detailed description of the finite-differencing for the prototypic MED erosion model was given in Reference 9. The additional finite difference equations in the EROSION/MOD1 code are described in Section 3.2.

From Eq. 2.13, it is clear that the terms representing the irreversible rate of internal energy conversion $\left(\varepsilon_{s} \overline{\bar{\tau}}_{s v}\right): \nabla \vec{v}_{s}$ are equivalent to all seven of the terms in the braces. Boundary condition ambiguities arise in evaluating these terms, as discussed by Lyczkowski et al. on pages 52-55. It has been our experience that the evaluation of Eq. $2.14 \mathrm{a}$ is subject to more discretization error than the direct evaluation of $\mathrm{Eq} .2 .14 \mathrm{~b}$, which constitutes a portion of the models given by Eqs. 2.14c and 2.14d.

Therefore, the discussion of the finite difference equations in this section is limited to the two ways to calculate the rate of irreversible conversion to internal energy in subroutines CHECK (default) and HAPPY. 


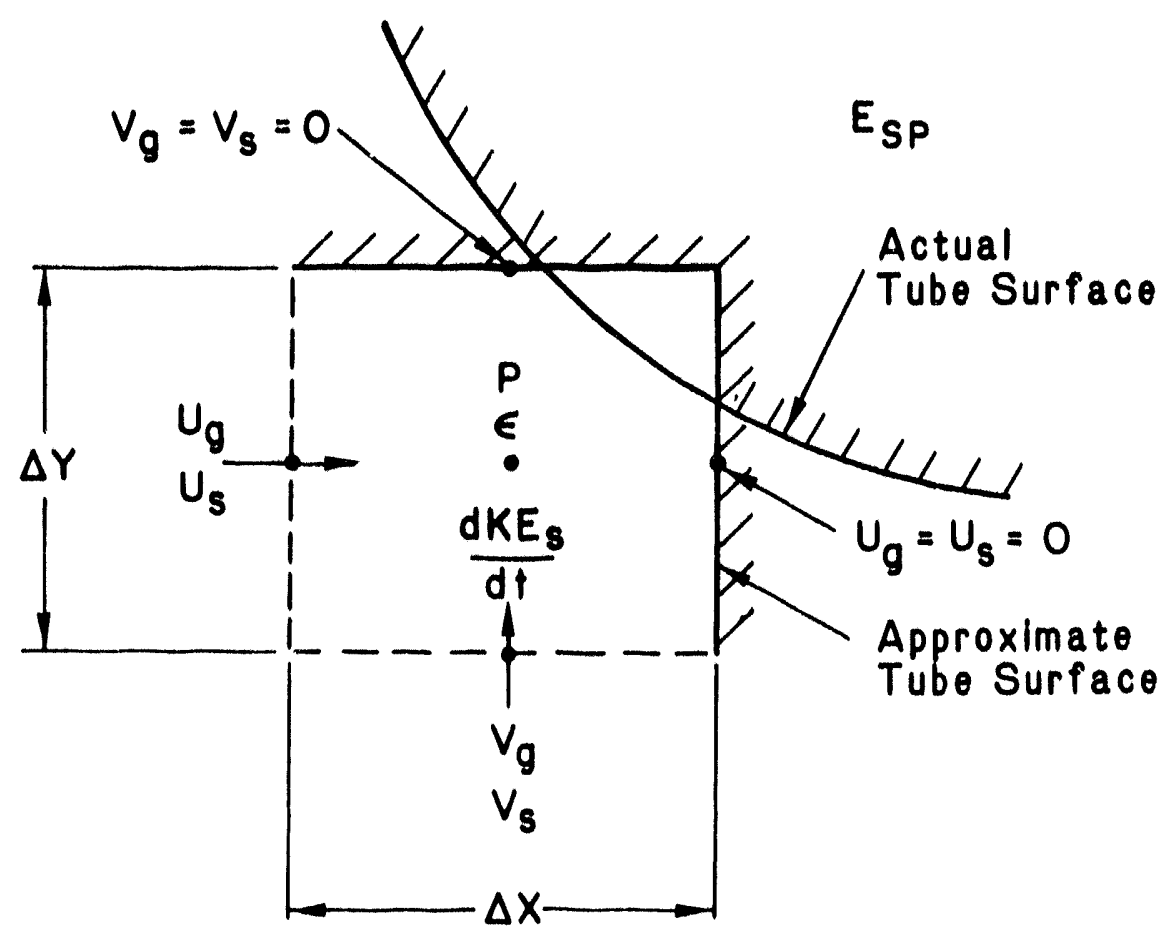

FIGURE 2 Coupling of Hydrodynamic and Erosion Models 


\subsection{Finlte Difference Approximations of the Irreversible Rate of Conversion to Internal Energy}

The total rate of irreversible conversion to internal energy $\varepsilon_{\mathrm{s}}\left(\overline{\bar{\tau}}_{\mathrm{s}}: \nabla \overrightarrow{\mathrm{v}}_{\mathrm{s}}\right)$ is comprised of four terms for a two-dimensional coordinate system. In $(x, z)$ Cartesian coordinates, they are given by

$$
\varepsilon_{s}\left(\overline{\bar{\tau}}_{\mathrm{sv}}: \nabla \overrightarrow{\mathrm{v}}_{\mathrm{s}}\right)=\varepsilon_{\mathrm{s}}\left[\tau_{\mathrm{xxs}} \frac{\partial \mathrm{U}_{\mathrm{s}}}{\partial \mathrm{x}}+\tau_{\mathrm{xzs}} \frac{\partial \mathrm{U}_{\mathrm{s}}}{\partial \mathrm{z}}+\tau_{\mathrm{zxs}} \frac{\partial \mathrm{V}_{\mathrm{s}}}{\partial \mathrm{x}}+\tau_{\mathrm{zzs}} \frac{\partial \mathrm{V}_{\mathrm{s}}^{\prime}}{\partial \mathrm{z}}\right]
$$

or

$$
\varepsilon_{s}\left(\overline{\bar{\tau}}_{\mathrm{sv}}: \nabla \overrightarrow{\mathrm{v}}_{\mathrm{s}}\right)=\varepsilon_{\mathrm{s}}\left\{\tau_{\mathrm{xxs}} \frac{\partial \mathrm{U}_{\mathrm{s}}}{\partial \mathrm{x}}+\tau_{\mathrm{zzs}} \frac{\partial \mathrm{V}_{\mathrm{s}}}{\partial \mathrm{z}}+\tau_{\mathrm{zzs}}\left(\frac{\partial \mathrm{U}_{\mathrm{s}}}{\partial \mathrm{z}}+\frac{\partial \mathrm{V}_{\mathrm{s}}}{\partial \mathrm{x}}\right)\right\}
$$

since $\tau_{\mathrm{zxs}}=\tau_{\mathrm{xzs}}$. The finite-differencing method used for Eq. 3.2 is the central differencing method, with the evaluation of the various velocity gradients at the cell center. Two subroutines were written, using the same basic equations for the derivatives. One accounts explicitly for the presence of the obstacle on these derivatives by forcing no-slip boundary conditions (subroutine CHECK) and is a special case of the general expression with no boundary condition prescriptions (subroutine HAPPY). The latter allows arbitrary boundary condition prescription (i.e., partial solids slip). ${ }^{20}$

The basic finite difference equations in subroutine HAPPY are, as in the K-FIX program:20

$$
\begin{aligned}
& {\left[\varepsilon_{\mathrm{s}}\left(\overline{\bar{\tau}}_{\mathrm{sv}}: \nabla \overrightarrow{\mathrm{v}}_{\mathrm{s}}\right)\right](\mathrm{IJ})=[1-\varepsilon(\mathrm{IJ})]\left\langle\tau_{\mathrm{xxs}}(\mathrm{IJ})\left[\frac{\mathrm{UL}(\mathrm{IJ})-\mathrm{UL}(\mathrm{IMJ})}{\mathrm{DX}}\right]+\tau_{\mathrm{xxs}}(\mathrm{IJ})\left[\frac{\mathrm{VL}(\mathrm{IJ})-\mathrm{VL}(\mathrm{IJM})}{\mathrm{DZ}}\right]\right.} \\
& +\tau_{\mathrm{xzs}}(\mathrm{IJ})\left[\frac{(\mathrm{VL}(\mathrm{IPJ})+\mathrm{VL}(\mathrm{IPJM}))-(\mathrm{VL}(\mathrm{IMJ})+(\mathrm{VL}(\mathrm{IMJM})}{(4 \mathrm{DX})}\right] \\
& +\tau_{\mathrm{xzzs}}(\mathrm{IJ})\left[\frac{(\mathrm{UL}(\mathrm{IJP})+\mathrm{UL}(\mathrm{IMJP}))-(\mathrm{UL}(\mathrm{IJM})+(\mathrm{UL}(\mathrm{IMJM}))}{(4 \mathrm{DZ})}\right]
\end{aligned}
$$

The indices used (IJ, IMJ, etc.) are shown in Figure 3. by

The finite difference expressions for the three shear terms $\tau_{x x s}, \tau_{z z s}$, and $\tau_{x z s}$ are given

$$
\begin{aligned}
& \tau_{\mathrm{xxs}}(\mathrm{IJ})=\mu_{\mathrm{s}}\left\{\frac{4}{3}\left[\frac{\mathrm{UL}(\mathrm{IJ})-\mathrm{UL}(\mathrm{IMJ})}{\mathrm{DX}}\right]-\frac{2}{3}\left[\frac{\mathrm{VL}(\mathrm{IJ})-\mathrm{VL}(\mathrm{IJM})}{\mathrm{DZ}}\right]\right\} \\
& \tau_{\mathrm{zzs}}(\mathrm{IJ})=\mu_{\mathrm{s}}\left\{\frac{4}{3}\left[\frac{\mathrm{UL}(\mathrm{IJ})-\mathrm{UL}(\mathrm{IMJ})}{\mathrm{DX}}\right]-\frac{2}{3}\left[\frac{\mathrm{VL}(\mathrm{IJ})-\mathrm{VL}(\mathrm{IJM})}{\mathrm{DZ}}\right]\right\} \\
& \tau_{\mathrm{xzzs}}(\mathrm{IJ})=\mu_{\mathrm{s}}\left\{\left[\frac{(\mathrm{VL}(\mathrm{IPJ})+\mathrm{VL}(\mathrm{IPJM}))-(\mathrm{VL}(\mathrm{IMJ})+\mathrm{VL}(\mathrm{IMJM}))}{(4 \mathrm{DX})}\right]+\right.
\end{aligned}
$$




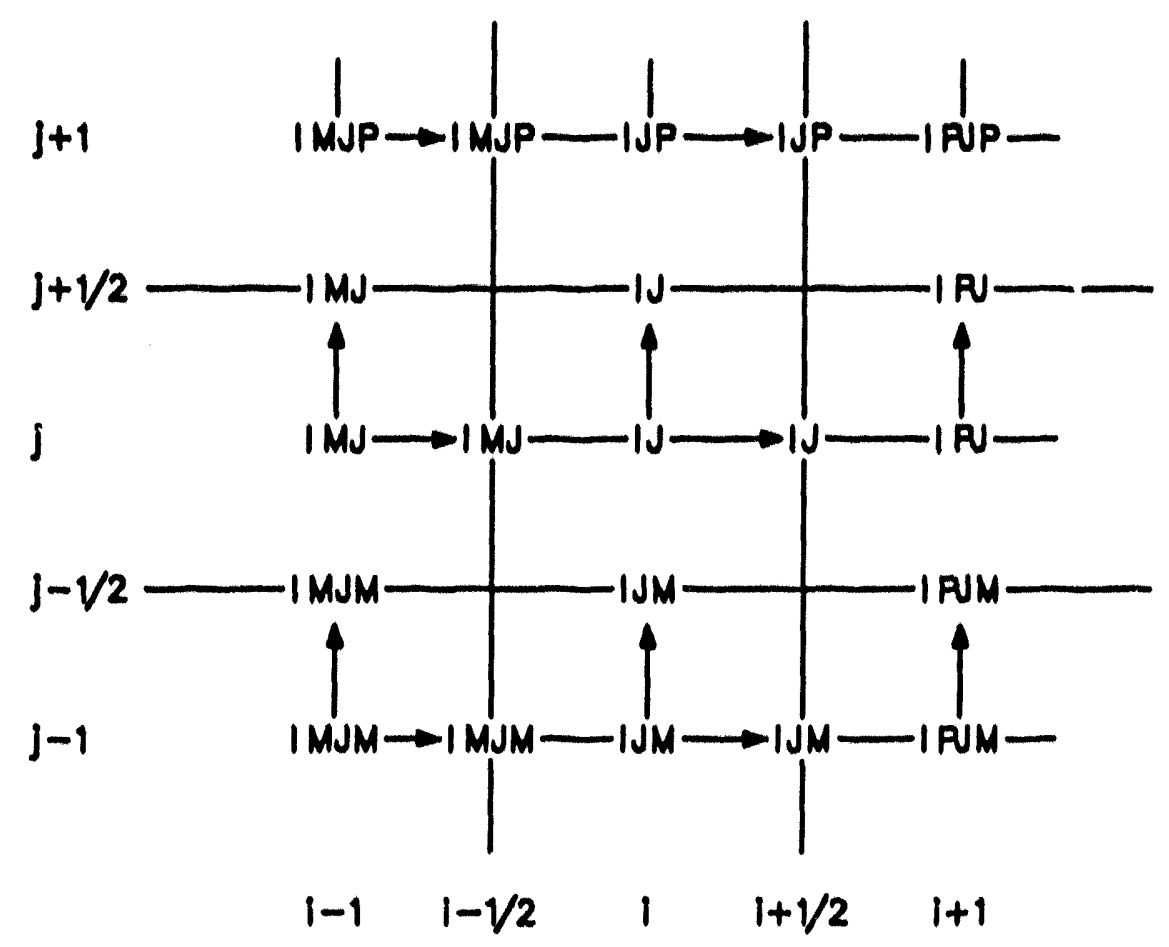

FIGURE 3 Single-Subscript Notation for Cell and Cell-Edge Quantities About Cell $(1, j)$ 


$$
\left.\left[\frac{(\mathrm{UL}(\mathrm{IJP})+\mathrm{UL}(\mathrm{IMJP}))-(\mathrm{UL}(\mathrm{IJM})+\mathrm{UL}(\mathrm{IMJM}))}{(4 \mathrm{DZ})}\right]\right\}
$$

The normal stresses $\tau_{\mathrm{xxs}}$ and $\tau_{z \mathrm{zs}}$ and velocity derivatives are differenced over one cell length, while two cell lengths are used for the off-diagonal shear stress $\tau_{x z s}$. These equations are general, in that no boundary condition, have been applied explicitly, and they hold for no-, free-, and partial-solids slip. Of course, if free slip is used, erosion is not computed for the cell.

The formulation given by Eqs. 3.3 and 3.4 (in subroutine HAPPY) was modified to account for no-slip solid boundary conditions by using the four flags discussed in Section 3.1. The results of this modification are contained in subroutine CHECK and are summarized below.

IFLAG $=1$ (no-slip solid surface above)

The shear stress $\tau_{x z s}$ becomes

$$
\tau_{\mathrm{xzs}}(\mathrm{IJ})=\mu_{\mathrm{s}}\left\{\left[\frac{\mathrm{VL}(\mathrm{IPJM})-\mathrm{VL}(\mathrm{IMJM})}{4 \mathrm{DX}}\right]+\left[\frac{-\mathrm{UL}(\mathrm{IJ})}{(\mathrm{DZ} / 2)}\right]\right\}
$$

and for the tangential velocities

$$
\begin{aligned}
& \frac{\partial U s}{\partial z}=-\frac{U L(I J)}{(D Z / 2)} \\
& \frac{\partial V s}{\partial x}=\frac{V L(I P J M)-V L(I M J M)}{(4 D X)}
\end{aligned}
$$

with the term $\frac{\partial U s}{\partial x}$ differenced over the interval $\Delta Z / 2$ next to the obstacle and the velocity at the surface of the obstacle set equal to zero.

Only the three terms above need to be modified, and the same logic is used for each change. Because of this, only the final result will be given for the other three flags.

IFLAG $=2$ (no-slip solid surface to the left)

$$
\begin{aligned}
& \tau_{\mathrm{xZ}}=\mu_{\mathrm{s}}\left\{\left[\frac{\mathrm{VL}(\mathrm{IJ})}{(\mathrm{DX} / 2)}\right]+\left[\frac{\mathrm{UL}(\mathrm{IJP})-\mathrm{UL}(\mathrm{IJM})}{(4 \mathrm{DZ})}\right]\right\} \\
& \frac{\partial \mathrm{Us}}{\partial \mathrm{z}}=\frac{\mathrm{UL}(\mathrm{IJP})-\mathrm{UL}(\mathrm{IJM})}{(4 \mathrm{DZ})} \\
& \frac{\partial \mathrm{Vs}}{\partial \mathrm{x}}=\frac{\mathrm{VL}(\mathrm{IJ})}{(\mathrm{DX} / 2)}
\end{aligned}
$$

IFLAG = 3 (no-slip solid surface below)

$$
\tau_{\mathrm{xz}}=\mu_{\mathrm{s}}\left\{\left[\frac{\mathrm{VL}(\mathrm{IPJ})-\mathrm{VL}(\mathrm{IMJ})}{(4 \mathrm{DX})}\right]+\left[\frac{\mathrm{UL}(\mathrm{IJ})}{(\mathrm{DZ} / 2)}\right]\right\}
$$




$$
\begin{aligned}
& \frac{\partial U s}{\partial z}=\frac{U L(I J))}{(D X / 2)} \\
& \frac{\partial V s}{\partial x}=\frac{V L(I P J)-V L(I M J)}{(4 D X)}
\end{aligned}
$$

IFLAG $=4$ (no-slip solid surface to the right)

$$
\begin{aligned}
& \tau_{\mathrm{Xz}}=\mu_{\mathrm{s}}\left\{\left[\frac{-\mathrm{VL}(\mathrm{IJ})}{(\mathrm{DX} / 2)}\right]+\left[\frac{\mathrm{UL}(\mathrm{IMJP})-\mathrm{UL}(\mathrm{IMJM})}{(4 \mathrm{DZ})}\right]\right\} \\
& \frac{\partial \mathrm{Us}}{\partial \mathrm{z}}=\frac{\mathrm{UL}(\mathrm{IMJP})-\mathrm{UL}(\mathrm{IMJM})}{(4 \mathrm{DZ})} \\
& \frac{\partial \mathrm{Vs}}{\partial \mathrm{x}}=\frac{-\mathrm{VL}(\mathrm{IJ})}{(\mathrm{DX} / 2)}
\end{aligned}
$$




\section{Calculation Procedure}

The prototype erosion computer code developed by Bouillard 10 and Lyczkowski et al. ${ }^{9}$ was highly problem specific and was devised to analyze the geometry of the thin twodimensional fluidized bed experiment built at the Illinois Institute of Technology (IIT). 21 Therefore, the computer program was modified to allow for different grid sizes and dimensions and multiple obstacles placed at arbitrary locations which aggregate shape(s) need not be rectangular. The original version of the erosion code served to develop the prototype monolayer energy dissipation erosion model discussed in Section 2.3 and to compare it with Finnie's erosion model. 9,10

The generalized EROSION/MOD1 code automatically determines the cell locations (IJ) where erosion will be computed by using the cell flag types, FL(IJ) generated by subroutine FLIC taken from the FLUFIX/MOD1 and MOD2 computer program.8,19 A computational (fluid) cell is denoted by $F L(I J)=1$, and a no-slip solid (rigid) boundary is indicated by $F L(I J)=3$. The EROSION/MOD1 program searches for locations where the cell in question is a fluid cell, $\mathrm{FL}(\mathrm{IJ})=1$, with an adjoining cell being a no-slip solid surface, $\mathrm{FL}(\mathrm{IJ})=3$, which is the same flag used for partial solids slip. ${ }^{19}$ Satisfaction of this condition defines a surface where erosion is to be calculated. Depending upon the position of the fluid cell witl respect to the solid cell (above, below, left, and right), an index, IFLAG, is then :tablished for cell (IJ) as

- Solid cell above fluid cell

- Solid cell to the left of the fluid cell

- Solid cell below fluid cell

- Solid cell to the right of the fluid cell

$$
\begin{aligned}
& \text { IFLAG }=1 \\
& \text { IFLAG }=2 \\
& \text { IFLAG }=3 \\
& \text { IFLAG }=4
\end{aligned}
$$

The finite-differencing scheme for the derivatives is modified on the basis of the IFLAG index, as discussed in Section 3.2. The finite-differencing scheme for the monolayer energy dissipation model boundary conditions is modified depending upon the IFLAG index to account for the orientation of the various surfaces with respect to the computational cell, as discussed in Section 3.2 .

The program keeps track of the IFLAG type and the location of the fluid cell next to the solid surface so that, in general, erosion can be calculated for multiple obstacles at any location within the bed. In addition, a user-selectable option gives the capability of transferring from the default form of the prototypic MED erosion model (Eq. $2.15 \mathrm{a}$ ) using hydrodynamic model $A$ (the ill-posed form) to hydrodynamic model B. ${ }^{21}$

The solids phase viscous stresses discussed in Section 3.2, which are also in FLUFIX/MOD2,19 are used to determine the kinetic energy's energy-dissipation rate per unit volume for the monolayer energy-dissipation models given by Eqs. 2.14a through 2.14d. This function required coding two terms involving the solids viscous stress: the reversible rate of work, $\nabla \cdot\left[\left(\varepsilon_{s} \overline{\bar{\tau}}_{s v}\right) \cdot \vec{v}_{s}\right]$, and the rate of irreversible conversion to internal energy, $\left[\left(\varepsilon_{\mathrm{s}} \overline{\bar{\tau}}_{\mathrm{sv}}\right): \nabla \vec{v}_{\mathrm{s}}\right]$. These two terms are evaluated outside the main program via subroutines so that extension to other solids viscous stress and solids viscosity models will not require modification of the main program. Each of these two terms can be calculated by using either of two methods selected by the user. 
The reversible rate of work done by the solids viscous stress can be evaluated by

1. Using velocities averaged at cell centers to compute cell-centered gradients as originally developed ${ }^{9}$ (subroutine VISWRK), and

2. Using cell-edge velocities similar to that done in the FLUFIX computer programs ${ }^{8,19}$ (subroutine VSCWRK) (default).

The rate of irreversible conversion to internal energy can be evaluated by:

1. Using the same formulation for this term as done in the K-FIX computer program, ${ }^{20}$ which uses cell-edge solids velocities (subroutine HAPPY); and

2. using a modification of the K-FIX formulation to better account for the presence of the obstacles by using the same cell-centered solids velocities (subroutine CHECK) (default).

The energy dissipation computations contained in this report used the second of each of the above two methods. The sensitivity and implications of these various methods have been investigated on a limited basis.

Cell-centered solids velocities are used to compute algebraic erosion models such as the Finnie ${ }^{2}$ and $\mathrm{NG}^{3}$ models described in this manual. 


\section{Global Structure of the EROSION/MOD1 Computer Program}

The global structure of the erosion computer program is described in this section. First, however, it is necessary to briefly describe the EROSION/MOD1 subroutines.

\subsection{EROSION/MOD1 Subroutines and Their Functions}

An alphabetical listing of the EROSION/MOD1 subroutines, together with brief descriptions, follows:

CHECK Calculates the rate of irreversible conversion to internal energy setting surface velocities to zero explicitly (default).

FINNIE Calculates the erosion for the Finnie erosion model.

FLIC Sets the cell flags on the basis of input data.

HAPPY Calculates the rate of irreversible conversion to internal energy.

INDEX,

INDEXA Calculates the indexes for array quantities and reflects cell quantities in the rigid cells.

KDRAGG Calculates the Richardson-Zaki equation for fluid-phase volume fraction $\varepsilon \geq 0.8 .8,19$

KDRAGL Calculates the Ergun equation for fluid-phase volume fraction $\varepsilon \geq 0.8 .8,19$

KDRAGS Calculates the values of the interphase friction function; calls KDRAGG and KDRAGL.

NEILSN Calculates the erosion for NG erosion model.

SETC Sets the C array, which is used to store equations of state or transport properties data, coefficients of functions, and related constants.

VISWRK Calculates the reversible rate of work done by solids viscous stress using cell centers.

VSCWRK Calculates the reversible rate of work done by solids viscous stress using cell edges (default).

\subsection{Erosion Program Structure Synopsis}

Figure 4 shows the data flow in and out of EROSION/MOD1. The input and control data are read from UNIT 5. Up to three sequential sets of post-processor files, which consist of IFR2 time-dependent porosity, pressure, and gas and solid velocities data sets called "dumps" 8,19 are read from UNITS 8-12,30-33, and 40-43. Figure 5 shows the flow structure and subroutine calling sequence. The cells are swept and the calculation procedure continues until IFR > IFR2. The time-averaging is then performed for the various energy dissipation and erosion rates and 


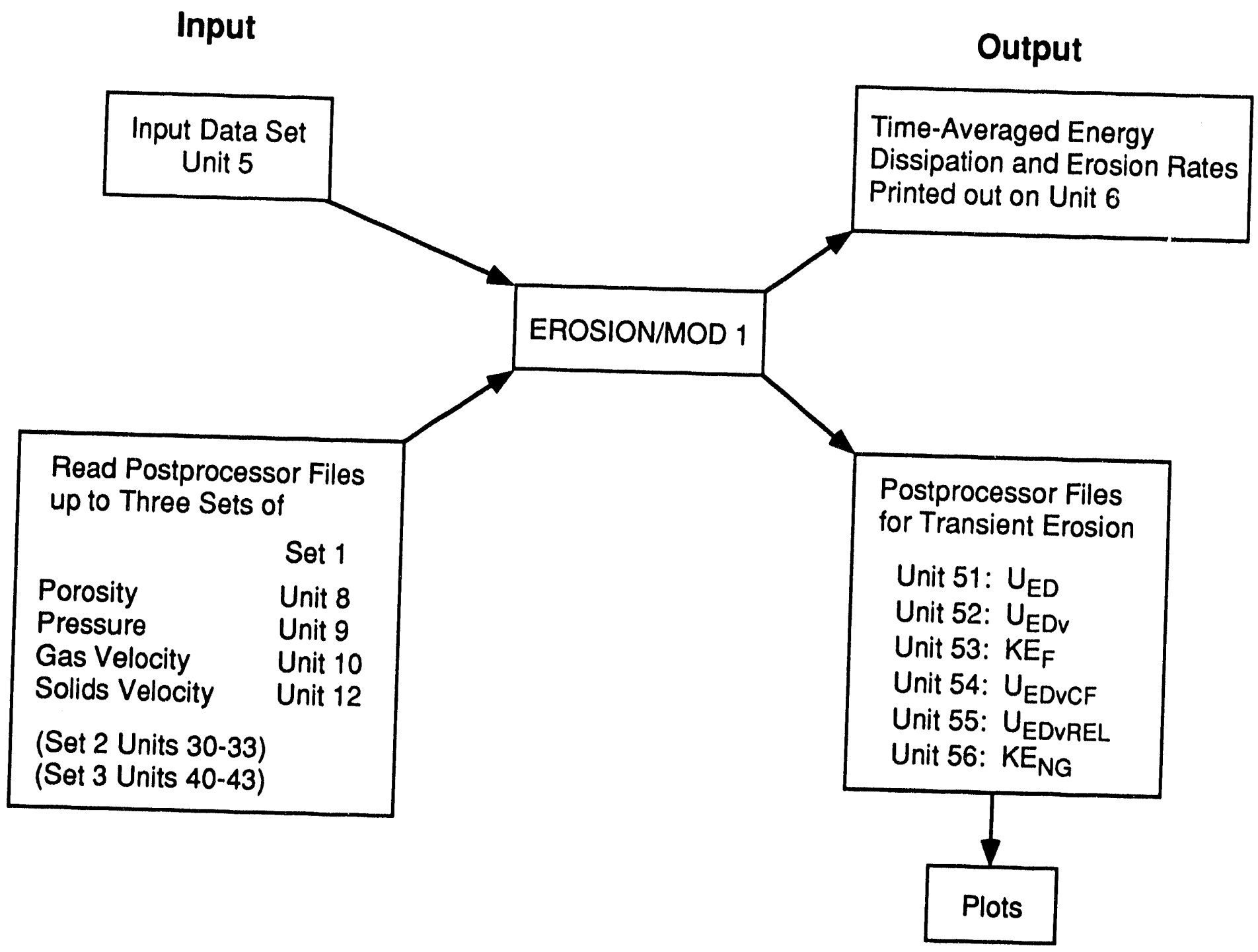

FIGURE 4 Data Flows in and out of EROSION/MOD1 


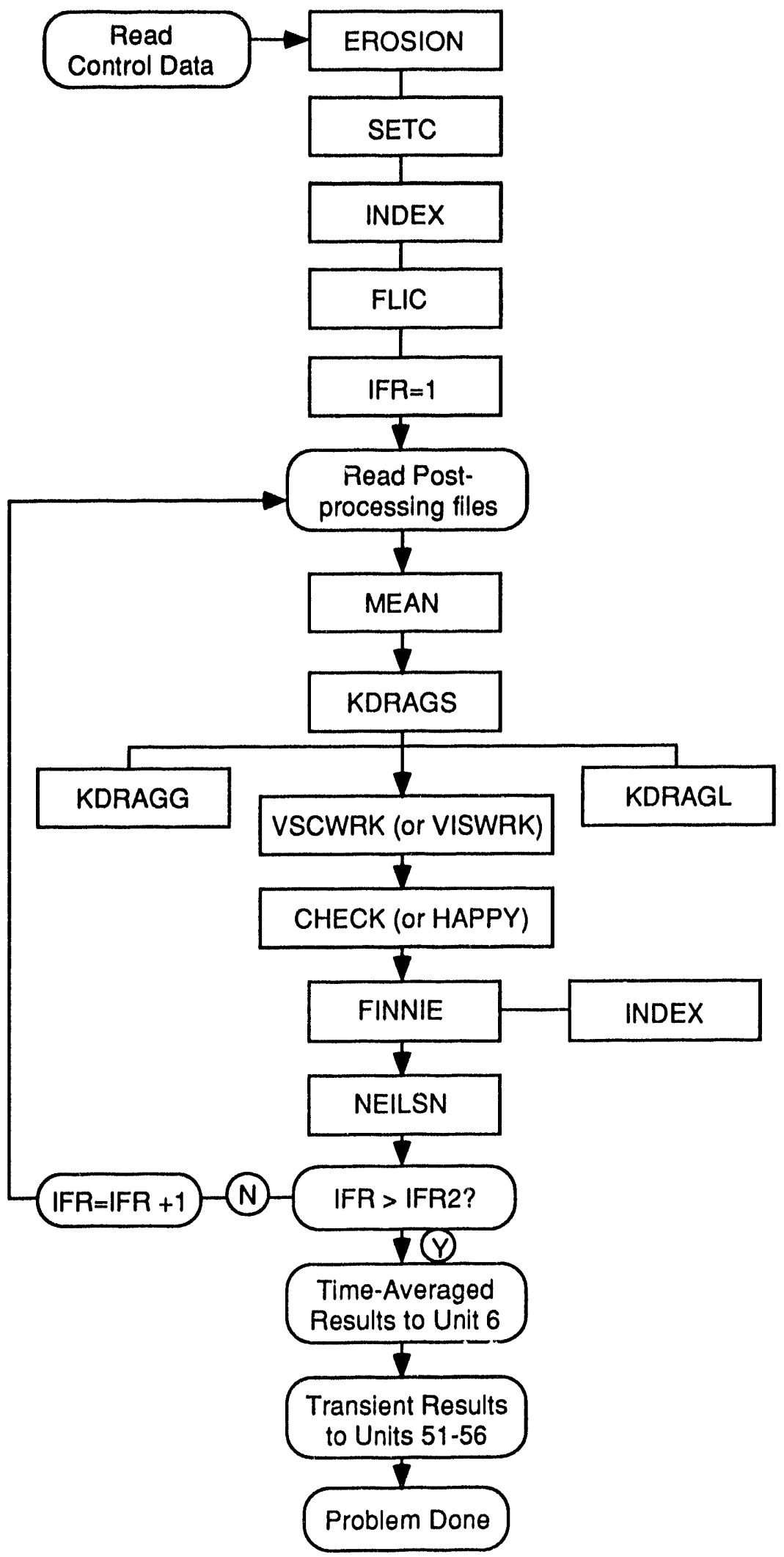

FIGURE 5 EROSION/MOD1 Program Structure and Subroutine Calling Sequences 
written to UNIT 6. These dissipation rates are then written to UNITS 51 through 56 for further analysis or plotting. 


\section{Description of EROSION /MOD1 Input Data}

In this section, the EROSION/MOD1 input data are described. These input data are a subset of the FLUFIX input data and must agree with those data.

\section{Line No. 1}

IFR0,IFR1,IFR2,IFR3 (Format 4I5)

IFRO = Dump number at which to start time-averaging (usually $=1$ ).

IFR $1=$ Number of dumps in first file.

IFR2 = Total number of dumps on all three files.

IFR3 = Number of dumps on first two files.

\section{Line No. 2}

IB2,JB2,IPRES,IDRAG (Format 4I5)

IB2 $=$ Total number of cells in $\mathrm{x}$ or $\mathrm{r}$ direction.

JB2 = Total number of cells in $\mathrm{y}$ or $\mathrm{z}$ direction.

IPRES $=0$ or 1

IPRES $=0$, selects Hydrodynamic Model A.

IPRES $=1$, selects Hydrodynamic Model B.

IDRAG $=0$ or 1

IDRAG $=0$, vector form of interphase drag is used.

IDRAG $=1$, scalar form of interphase drag is used.

\section{Line No. 3}

NO, DX, DZ,BHITE (Format I12, 3F12.4)

NO $=$ Number of Interior Obstacle Cells.

DR $=\delta r$ or $\delta \mathrm{x}$, the cell dimension in the $\mathrm{r}$ or $\mathrm{x}$ direction, $\mathrm{cm}$.

$\mathrm{DZ}=\delta \mathrm{z}$ or $\delta \mathrm{y}$, the cell dimension of the $\mathrm{z}$ or $\mathrm{y}$ direction, $\mathrm{cm}$.

BHITE $=$ Height of fluidized bed where solids are present, $\mathrm{cm}$.

\section{Line No. 4}

$\operatorname{KFLIN(M),~M~=~1,4~(Format~6I12)~}$ 
KFLIN(M) = Cell flag types for the inflow boundaries, BOTTOM-L and BOTTOM-R openings $(M=1,2)$ and LEFT $=B$ and LEFT-T openings $(M=3,4)$. Refer to Figure 9 of References 8 or 19 for lines 4 through 9.

Line No. 5

FLO(M),M = 1,4 (Format 4F12.4)

FLO(1) and FLO(2) are the $x$ or $r$ coordinates of the left inflow opening on the BOTTOM-L boundary, $\mathrm{cm} ; \mathrm{FLO}(3)$ and $F L O(4)$ are the $\mathrm{x}$ or $\mathrm{r}$ coordinates of the right inflow opening on the BOTTOM-R boundary, $\mathrm{cm}$.

Line No. 6

FLO(M),M = 5,8 (Format 4F12.4)

FLO(5) and FLO(6) are the $y$ or $z$ coordinates of the bottom inflow opening on the LEFT-B boundary, $\mathrm{cm}$; FLO(7) and $\mathrm{FLO}(8)$ are the $y$ or $z$ coordinates of the top inflow opening on the LEFT-T boundary, $\mathrm{cm}$.

Line No. 7

KFLOUT(M), $M=1,4$ (Format 6I12)

KFLOUT(M) = Cell flag types for the outflow boundaries, TOP-L and TOP-R openings $(M=1,2)$ and RIGHT-B and RIGHT-T openings $(M=3,4)$.

Line No. 8

FLO(M), $M=9,12$ (Format 4F12.4)

$F L O(9)$ and $F L O(10)$ are the $x$ or $r$ coordinates of the left outflow opening on the TOP-L boundary, cm; FLO(11) and FLO(12) are the $x$ or $r$ coordinates of the right outflow opening on the TOP-R boundary, $\mathrm{cm}$.

Line No. 9

FLO(M), $\mathrm{M}=13,16$ (Format 4F12.4)

$\mathrm{FLO}(13)$ and $\mathrm{FLO}(14)$ are the $y$ or $z$ coordinates of the bottom outflow opening on the RIGHT-B boundary, cm; FLO(15) and FLO(16) are the $y$ or $z$ coordinates of the top outflow opening on the RIGHT-T boundary, $\mathrm{cm}$.

Line No. 10

NSL(M), $M=1,4$ (Format 4I12)

NSL(M) indicates free-slip or no-slip boundary conditions for rigid walls around the computing mesh perimeter. A value of 0 for free-slip or 1 for no-slip is assigned for the bottom $(M=1)$, left $(M=2)$, top $(M=3)$, and right $(M=4)$ boundaries, in that order. The assigned values are ignored across inflow or outflow openings. This flag overrides KFLIN or KFLOUT $=2$ or 3 . 


\section{Line No. $10+\mathrm{N}^{*}$}

NSO(N), (OB(M,N), $M=1,4$ ) (Format $112,4 \mathrm{~F} 12.4$ )

$\mathrm{NSO}(\mathrm{N})=0$ for free-slip boundary conditions for obstacle $\mathrm{N}$.

$=1$ for no-slip boundary conditions for obstacle $\mathrm{N}$.

$\mathrm{OB}(1, \mathrm{~N})=\mathrm{x}$ or $\mathrm{r}$ coordinate of the left side of obstacle $\mathrm{N}, \mathrm{cm}$.

$\mathrm{OB}(2, \mathrm{~N})=\mathrm{x}$ or $\mathrm{r}$ coordinate of the right side of obstacle $\mathrm{N}, \mathrm{cm}$.

$\mathrm{OB}(3, \mathrm{~N})=\mathrm{y}$ or $\mathrm{z}$ coordinate of the bottom of obstacle $\mathrm{N}, \mathrm{cm}$.

$\mathrm{OB}(4, \mathrm{~N})=\mathrm{y}$ or $\mathrm{z}$ coordinate of the top of obstacle $\mathrm{N}, \mathrm{cm}$.

\section{Line No. $11+\mathrm{N}$}

SLOPE, THZERO, RLO (Format 3F10.6)

SLOPE, THZERO, parameters for the elastic modulus $\mathrm{G}=\exp [-\operatorname{SLOPE}(\varepsilon-\mathrm{THZERO})]$, dynes $/ \mathrm{cm}^{2}$.

$\mathrm{RLO}=$ Density, $\mathrm{g} / \mathrm{cm}^{3}$ (default value is $2.611 \mathrm{~g} / \mathrm{cm}^{3}$ ).

\section{Line No. $12+N$}

VPRIM,THPRIM,MUL (Format 3F10.6)

VPRIM, THPRIM not used.

MUL = solids viscosity, poise. The default value is 1.0 poise.

\section{Line No. $13+N$}

DP,HARD,PHI,MMUG (Format 3F10.5, F12.8)

$\mathrm{DP} \quad=$ Particle diameter, $\mathrm{cm}$.

HARD = Eroding surface hardness, $\mathrm{kgf} / \mathrm{mm}^{2}$.

PHI $=$ Particle sphericity, $\phi_{\mathrm{S}}\left(0<\phi_{\mathrm{S}} \leq 1\right)$.

MMUG = Fluid viscosity, poise, used in the interphase drag. The default value is 1.82 $\times 10^{-4}$ poise.

\footnotetext{
${ }^{*} \mathrm{~N}=1, \mathrm{~N} 0, \mathrm{~N} 0>0$
} 
Default Values:

DP, $0.0503 \mathrm{~cm}$; HARD, $30 \mathrm{kgf} / \mathrm{mm}^{2}$ (294 MPa); PHI, 0.86; MMUL, 1.0 poise; MMUG, $1.82 \times 10^{-4}$ poise; RLO, $2.611 \mathrm{~g} / \mathrm{cm}^{3}$; MUL, 1.0 poise. 


\section{Sample Problem for a Fluldized Bed}

The geometry of the sample problem given here for a fluidized bed is shown in Figure 6. This sample problem is the same as the one described in the FLUFIX/MOD2 Users Manual. 19 The computational region is $19.685 \mathrm{~cm}$ wide and $58.44 \mathrm{~cm}$ high. The cell dimensions are $\Delta x=\delta x=0.635 \mathrm{~cm}$ and $\Delta y=\delta y=4.87 \mathrm{~cm}$, so that the number of computational cells is 31 in the $x$ direction and 12 in in the $y$ direction, for a total of 372. In Figure 6, the numbers in parentheses refer to key cell numbers $(I, J)$. Symmetry about the central jet is assumed; hence, the actual bed width is $39.37 \mathrm{~cm}$. The jet half-width is $0.635 \mathrm{~cm}$ (one cell width). The jet velocity is $578 \mathrm{~cm} / \mathrm{s}$, and the secondary air velocity of $26.0 \mathrm{~cm} / \mathrm{s}$ maintains the bed without a jet at minimum fluidization. The particle diameter is $503 \mu \mathrm{m}$, and the density is $2.44 \mathrm{~g} / \mathrm{cm}^{3}$. The obstacle is placed two nodes above the jet and is two nodes $(1.27 \mathrm{~cm})$ wide by two nodes $(9.74$ $\mathrm{cm}$ ) high. Because the initial bed height is $29.22 \mathrm{~cm}$ (six cells high), the obstacle lies completely within the bed. Although this configuration is not typical of FBC geometries, it was selected because (1) it is similar to the model without the obstacle, so that prior experience is relevant, and (2) it serves to further validate the hydrodynamic model.

The boundary conditions are described here. At the inlet $(\mathrm{J}=2)$, the axial gas velocity of $26.0 \mathrm{~cm} / \mathrm{s}$ is set equal to the minimum fluidization superficial velocity as computed from the Ergun equation (with solids velocity set to zero) by using an assumed gas volume fraction at minimum fluidization, $\varepsilon_{\mathrm{mf}}$, of $(0.42$. Because no solids are entering, the inlet porosity is set to 1.0. The pressures in the dummy cells at the top $(\mathrm{J}=14)$ are set equal to atmospheric pressure $\left(1.013 \times 10^{5} \mathrm{~Pa}\right)$, and $\mathrm{V}_{\mathrm{S}}=0$ at the exit $(\mathrm{J}=13)$; that is, wire mesh is simulated to prevent solids carry-over. The pressure in the bottom row of dummy cells $(\mathrm{J}=1)$ is set equal to atmospheric pressure plus 1.2 times the total bed weight $\left(1.0549 \times 10^{5} \mathrm{~Pa}\right)$. On all solid surfaces except the inlet, outlet, and line of symmetry, no-slip boundary conditions are used (i.e., normal and tangential velocities for each phase are set equal to zero). Free-slip boundary conditions are used along the line of symmetry and at the inlet and outlet. Initially, the radial gas velocity is zero, the axial gas velocity is equal to the interstitial gas velocity at minimum fluidization, and the solids radial and axial velocities are zero. The bed porosity is uniform at 0.42 . The initial pressure distribution corresponds to the hydrostatic bed height. At time, $t$, greater than zero $(()+)$, the gas flow through the jet is increased to $578 \mathrm{~cm} / \mathrm{s}$. A fixed-time stop of $(0.1 \mathrm{~ms}$ is used. Typical running time on an IBM 3033 computer is approximately one hour for each second of transient time. The running time is approximately four times faster on a CRAY-XMP.

The FLUFIX/MOD2 code was run to $0.4 \mathrm{~s}$ with post-processing files produced every $1(0)$ time steps $(0.005 \mathrm{~s})$ for a total of 80 "dumps." The input data and sample output can be found in the users manual. 19 The EROSION/MOD1 sample problem input is given in Table 2. The EROSION input data file can easily be generated from the FLIJFIX input data file by using a text editor. All of the input values must agree. There are no checks for inconsistencies.

Table 3 presents the sample problem output. The output beginning at line 46 (TIME = $0.0050)$ and ending at line 63 summarizes all the cells IJ for which erosion has been computed. These surfaces are numbered for each IJ and are denoted by $K=1$ through $K=16$ in column 3 , lines 47 through 63. The quantities RES(K), TAUV(K), and VISC(K) are not of interest. These quantities represent partial results for one of the MED erosion models evaluated by using values at the first dump.

The table of flags, FL, starting at line 31 and ending at line 44 , defines the entire computational domain. Erosion is only computed for surfaces when the flag $F L=1$ is next to a 


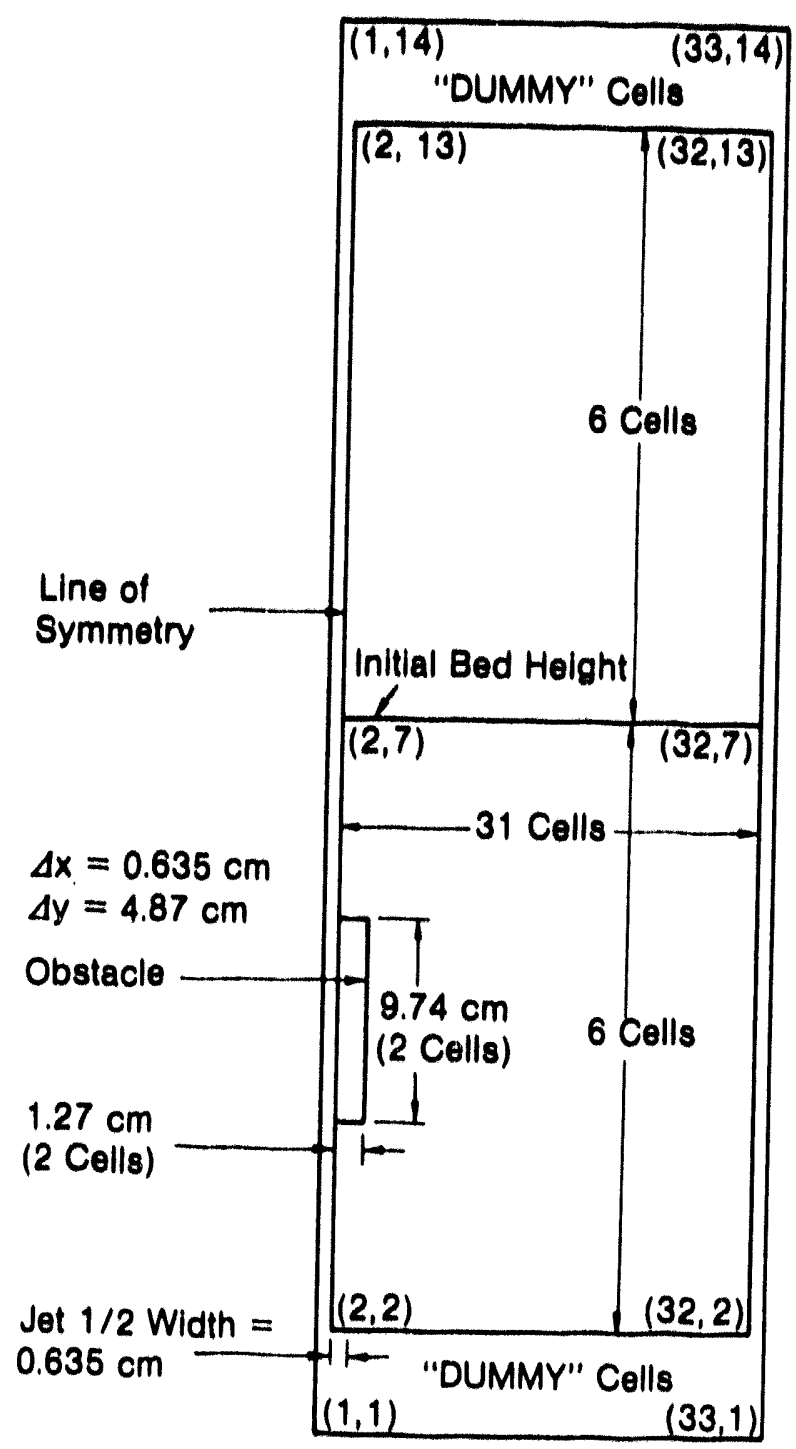

FIGURE 6 EROSION Sample Problem Geometry 
TABLE 2 EROSION/MOD1 Sample Problem Input Data File

LneNe

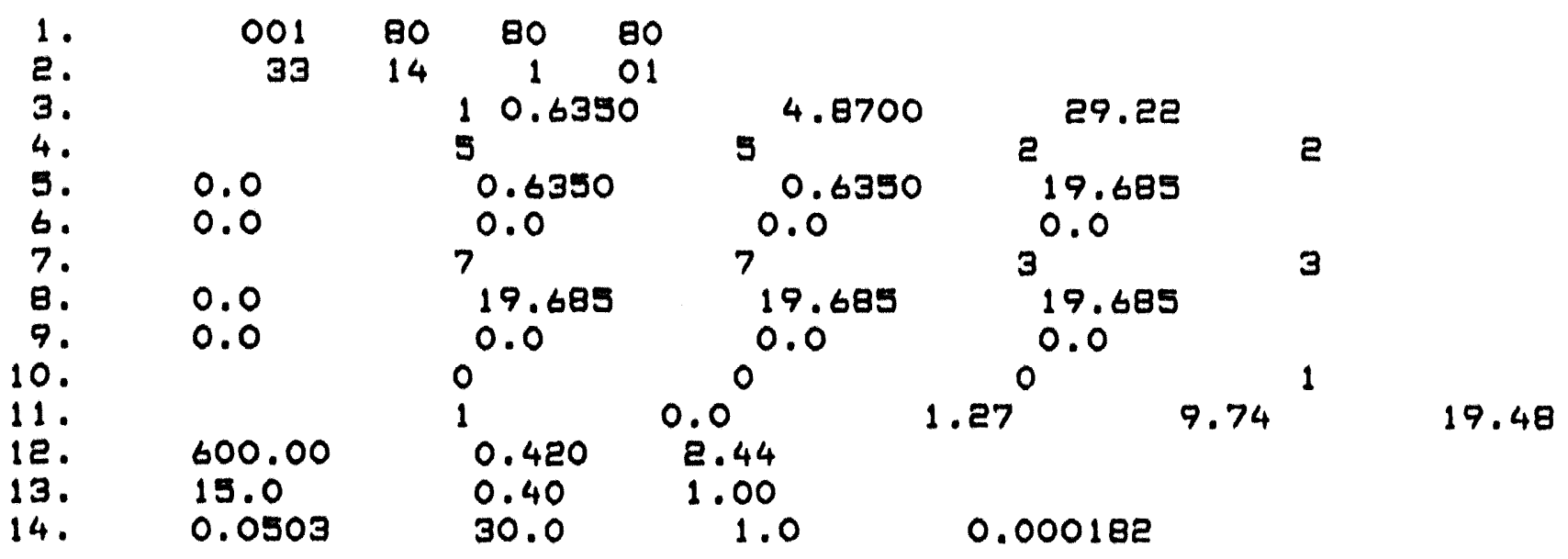


TABLE 3 EROSION/MOD1 Sample Problem Output

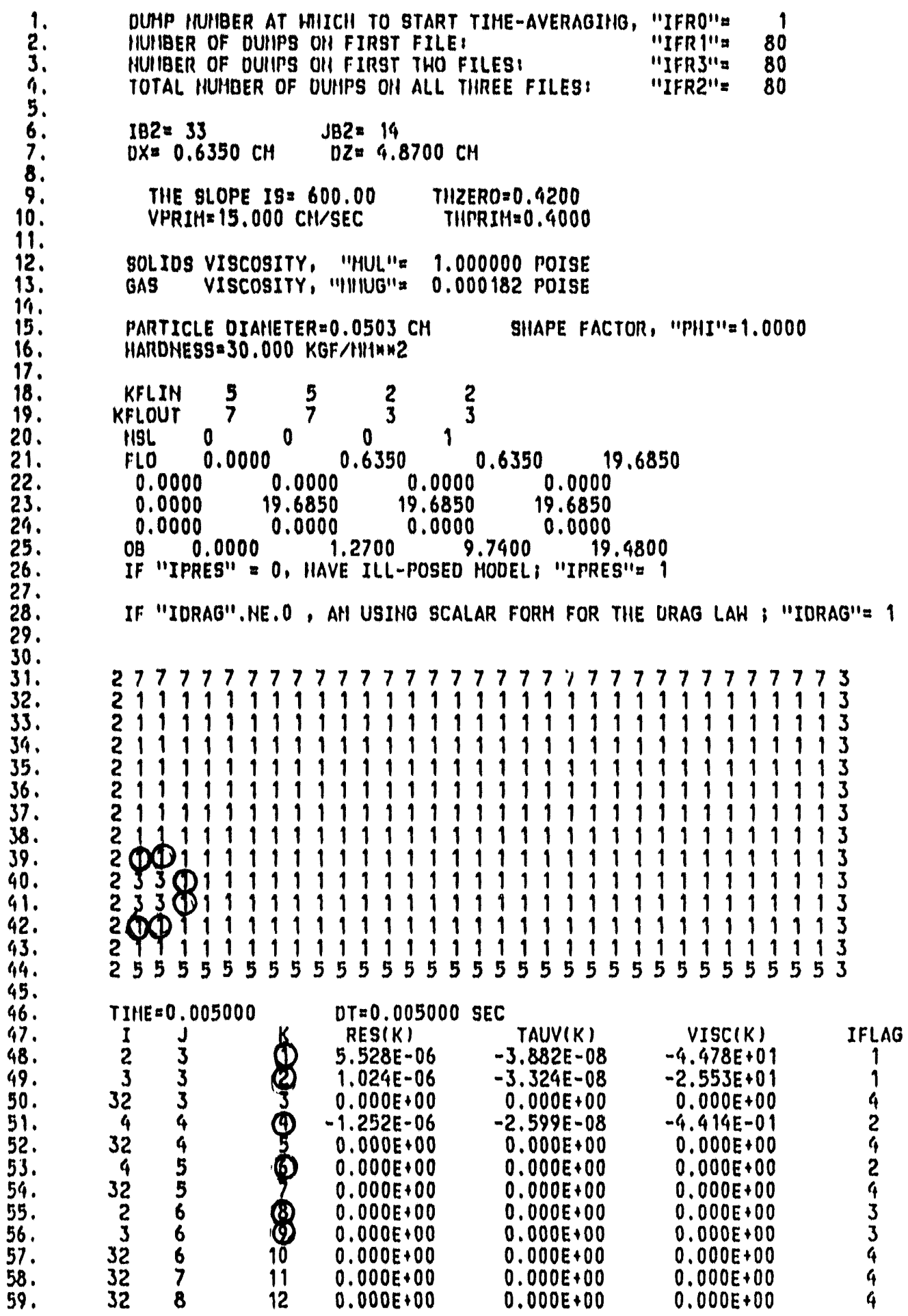


TABLE 3 (cont'd)

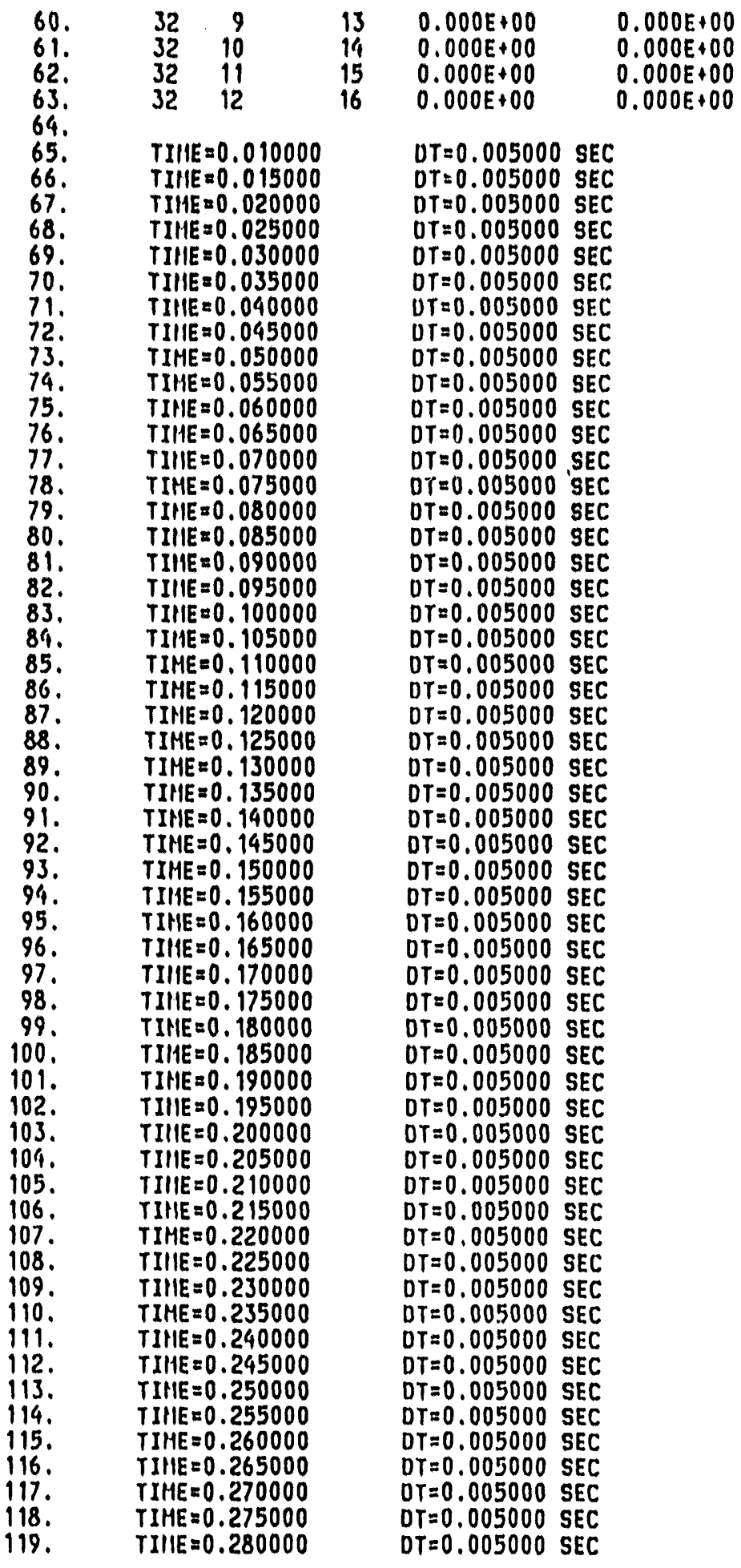


TABLE 3 (cont'd)

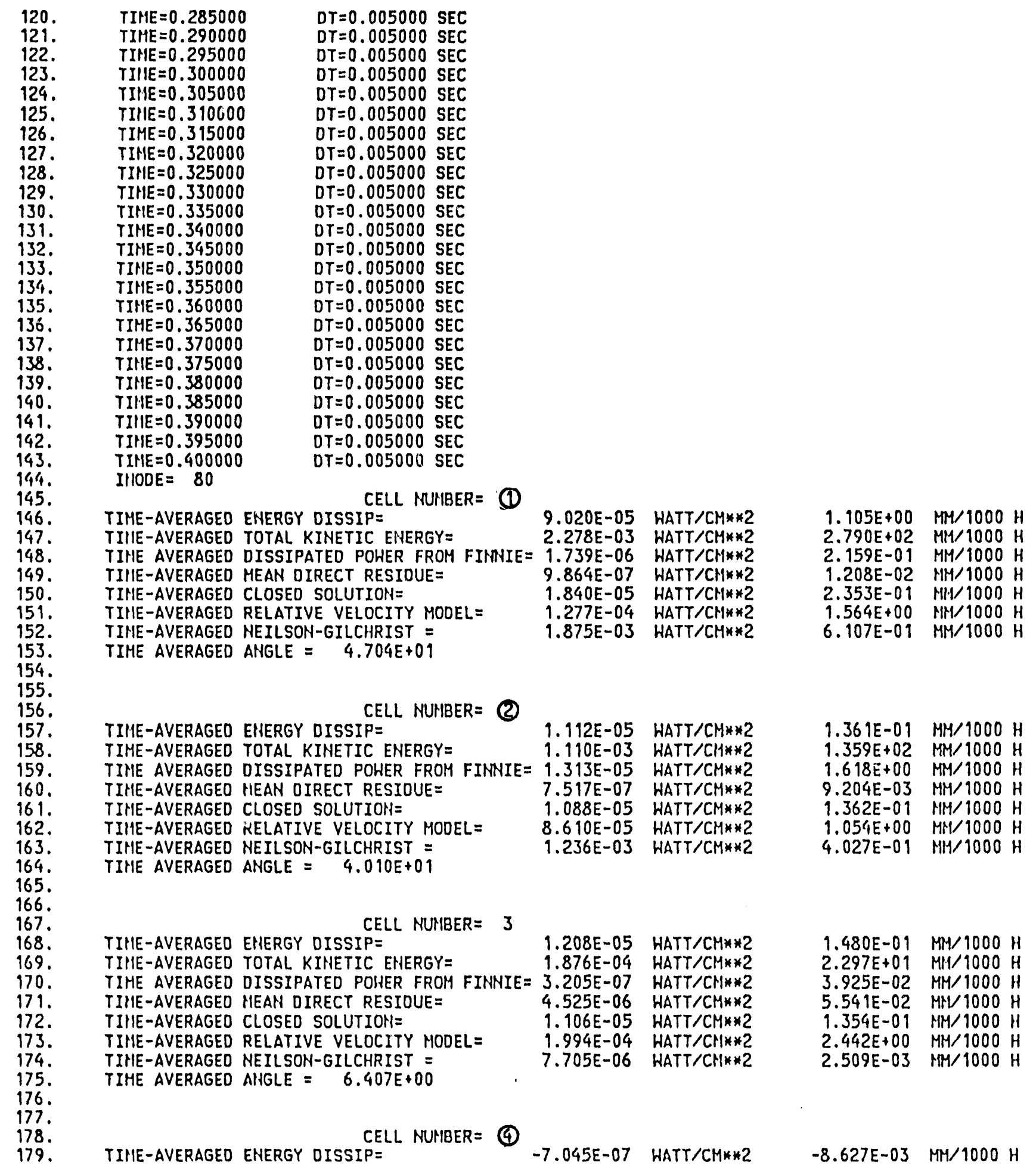


TABLE 3 (cont'd)

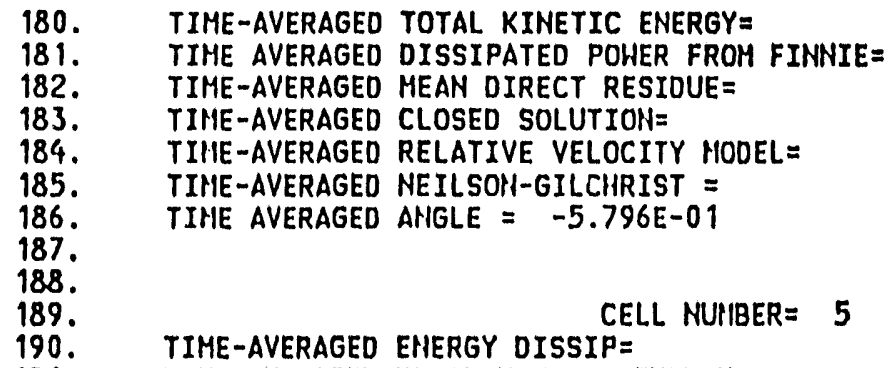

191.

192.

193.

194.

195.

196.

197.

198.

199.

200.

201.

202.

203.

204.

205.

206.

207.

208.

209.

210.

211.

212.

213.

214.

215.

216.

217.

218.

219.

220.

221.

222.

223.

224.

225.

226.

227.

228.

229.

230.

231.

232.

233.

234.

235.

236.

237.

238.

239.

TIHE-AVERAGED TOTAL KIHETIC ENERGY=

TIIIE-AVERAGED NEAN DIRECT RESIDUE=

TIME-AVERAGED CLOSED SOLUTION=

TIHE-AVERAGEO RELATIVE VELOCITY MOOEL=

TIME-AVERAGED NEILSON-GILCHRIST =

TIIHE AVERAGED AIIGLE $=9.119 \mathrm{E}-01$

CELL NUMBER = (6)

TIME-AVERAGED EHERGY DISSIP=

TIME-AVERAGED TOTAL KINETIC ENERGY=

TIME-AVERAGED MEAN DIRECT RESIDUE=

TIME-AVERAGED CLOSED SOLUTION=

TIHE-AVERAGED NEILSOH-GILCIIRIST =

TIIIE AVERAGED ANGLE $=-1.372 E-01$

\section{CELL NUMBER $=7$}

TIME-AVERAGED EHERGY DISSIP=

TIHE-AVERAGED TOTAL KINETIC ENERGY=

TIME-AVERAGEO CLOSED SOLUTION=

TIME-AVERAGED RELATIVE VELOCITY MODEL=

TIHE-AVERAGED NEILSON-GILCHRIST = TIHE AVERAGED ANGLE $=0.000 E+00$

TIME-AVERAGEO EMIERGY DISSIP=

CELL NUMBER $=$

TIME-AVERAGED TOTAL KINETIC ENERGY=

\section{(8)}

TIIIE-AVERAGED MEAN DIRECT RESIDUE=

TIME-AVERAGED RELATIVE VELOCITY MODEL =

TIME-AVERAGED NEILSON-GILCHRIST =

TIME AVERAGED ANGLE $=-1.799 \mathrm{E}+01$

CELL NUMBER = (9)

TIITE-AVERAGED ENERGY DISSIP $=$

TIIIE-AVERAGED TOTAL KINETIC ENERGY=

TIME-AVERAGED MEAHI DIRECT RESIDUE=

TIME-AVERAGED CLOSEO SOLUTION=
2.236E-03 $4.852 E-07$ $1.382 E-05$ 2. $377 E-05$ 2.792E-04 $1.450 E-05$

WATT/CMK*2 WATT/CM**2 WATT/CH**2 WATT/CH**2 HATT/CH**2 HATT/CH**2

$1.576 E-05$

9.813E-06

$1.223 E-03$

TIME AVERAGED DISSIPATED POHER FROH FINNIE $=8.731 E-08$

$1.177 \mathrm{E}-05$

$2.423 E-05$

2.555E-04

2. 127E-06

1.230E-05

8.653E-04

$\begin{array}{ll}\text { TIIIE AVERAGED DISSIPATED POWER FROM FINNIE }=0.000 E+00 \\ \text { TIHIE-AVERAGED MEAN DIRECT RESIDUE }= & 1.294 \mathrm{E}-05\end{array}$

$3.189 \mathrm{E}-05$

2. $157 \mathrm{E}-04$

$0.000 E+00$

WATT/CM**2 WATT/CM**2 WATT/CH**2 WATT/CH**2 WATT/CM**2 HATT/CM**2

HATT/CM**2

TIME AVERAGED DISSIPATED POWER FROM FINNIE $=8.228 E-08$

$3.645 E-07$

$1.325 \mathrm{E}-05$

$4.010 E-05$

$6.789 E-05$

$-1.767 E-05$

$2.824 E-04$

WATT/CH**2

TIME AVERAGED DISSIPATED POWER FROM FINNIE $=4.467 \mathrm{E}-07$

$1.188 \mathrm{E}-06$

1.360E-05

5.012E-05

HATT/CM**2

HATT/CM**2

HATT/CM**2

HATT/CM**2

HATT/CM**2
$2.738 \mathrm{E}+02 \mathrm{MM} / 1000 \mathrm{H}$ $5.941 \mathrm{E}-02 \mathrm{MM} / 1000 \mathrm{H}$ $1.692 \mathrm{E}-01 \mathrm{MHY} / 1000 \mathrm{HI}$ $2.960 \mathrm{E}-01$ HWV $1000 \mathrm{H}$ $3.419 \mathrm{E}+00 \mathrm{HM} / 1000 \mathrm{H}$

$4.722 \mathrm{E}-03 \mathrm{HM} / 1000 \mathrm{H}$

1.930E-01 MM/1000 H $6.646 \mathrm{E}+01 \mathrm{HH} / 1000 \mathrm{H}$ 1.691E-01 HN/ $1000 \mathrm{H}$ $1.162 \mathrm{E}-01 \mathrm{HH} / 1000 \mathrm{H}$ 2.975E-01 MM/1000 H $2.590 \mathrm{E}+00 \mathrm{MH} / 1000 \mathrm{H}$ $9.779 \mathrm{E}-03 \mathrm{HM} / 1000 \mathrm{H}$

1.202E-01 HM/1000 H $1.498 \mathrm{E}+02 \mathrm{HM} / 1000 \mathrm{H}$ 1.069E-02 MM/1000 H 1.441E-01 MHV $1000 \mathrm{H}$ 2.967E-01 MM/1000 H $3.129 E+00 \quad H M / 1000 \mathrm{H}$ 6.926E-04 MM/1000 H

1.506E-01 MM/1000 H $1.060 \mathrm{E}+02 \mathrm{NH} / 1000 \mathrm{H}$ $0.000 \mathrm{E}+00 \mathrm{MH} / 1000 \mathrm{H}$ $1.584 \mathrm{E}-01$ HII/ $1000 \mathrm{H}$ $3.905 \mathrm{E}-01 \mathrm{HH} / 1000 \mathrm{H}$ $2.641 \mathrm{E}+00 \mathrm{MPI} / 1000 \mathrm{H}$ $0.000 \mathrm{E}+00 \mathrm{MII} / 1000 \mathrm{HI}$
$-2.164 E-01$
$3.458 E+01$
5. $440 \mathrm{E}-02$
$1.454 E-02$
$1.675 \mathrm{E}-01$
6.137E-01
$M M / 1000 \mathrm{H}$ $M M / 1000 \mathrm{H}$ All. $/ 1000 \mathrm{H}$ $M M / 1000 \mathrm{H}$ $\mathrm{MPV} / 1000 \mathrm{HI}$ HIV $1000 \mathrm{H}$ 
TABLE 3 (cont'd)

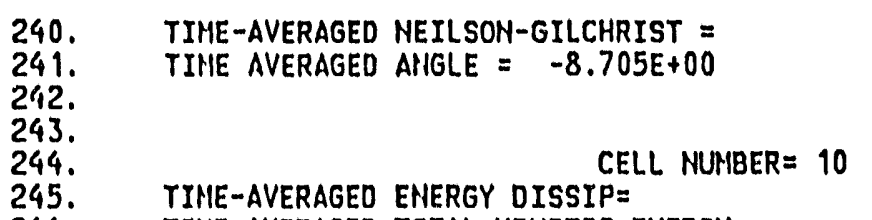

246.

247.

248.

249.

250.

251.

252.

253.

254.

255.

256.

257.

258.

259.

260.

261.

262.

263.

264.

265.

266.

267.

268.

269.

270.

271.

272.

273.

274.

275.

276.

277.

278.

279.

280.

281.

282.

283.

284.

285.

286.

287.

288.

289.

290.

291.

292.

293.

294.

295.

296.

297.

298.

299.

TIIIE-AVERAGED TOTAL KINETIC ENERGY=

TIME-AVERAGED MEAN DIRECT RESIOUE=

TIME-AVERAGED CLOSED SOLUTION=

TIIIE-AVERAGED RELATIVE VELOCITY MODEL=

TIHE-AVERAGED NEILSON-GILCIIRIST =

TIIIE AVERAGED AIIGLE $=1.176 \mathrm{E}+00$

TIHE-AVERAGED EHIERGY DISSIP=

TIHE-AVERAGED TOTAL KINETIC ENERGY=

TIHE-AVERAGED HEAN DIRECT RESIDUE=

TIME-AVERAGED CLOSEO SOLUTIOH=

TIHE-AVERAGED RELATIVE VELOCITY MODEL=

TIHE-AVERAGED NEILSOH-GILCHRIST =

TIME AVERAGED ANGLE $=-4.313 E-02$

CELL NUHBER $=12$

TIHE-AVERAGED ENERGY DISSIP=

TIME-AVERAGED TOTAL KINETIC ENERGY=

TIHE-AVERAGED MEAN DIRECT RESIDUE=

TINE-AVERAGED CLOSED SOLUTION=

TIHE-AVERAGED RELATIVE VELOCITY MODEL=

TIME-AVERAGED NEILSON-GILCIRIST =

TIIIE AVERAGED ANGLE $=9.556 \mathrm{E}-01$

CELL NUMBER $=13$

TIME-AVERAGED ENERGY DISSIP =

TIME-AVERAGED TOTAL KINETIC ENERGY=

TIIIE-AVERAGED MEAN DIRECT RESIDUE=

TIIIE-AVERAGED CLOSED SOLUTION=

TIHE-AVERAGED RELATIVE VELOCITY HOOEL=

TIHE-AVERAGED NEILSON-GILCHRIST =

TIIIE AVERAGED AlIGLE $=9.998 \mathrm{E}-01$

CELL HUMBER $=14$

TIME-AVERAGED EHERGY DISSIP=

TIHE-AVERAGED TOTAL KINETIC ENERGY=

TIIIE-AVERAGED HIEAII DIRECT RESIDUE =

TIME-AVERAGED CLOSED SOLUTIOH=

TIIIE-AVERAGED RELATIVE VELOCITY MOOEL=

TIHE-AVERAGED NEILSOH-GILCHRIST =

TIHE AVERAGED AYGLE $=7.724 E-02$

4.720E-05 WATT/CM**2 1.537E-02 MM/1000 H

$-5.314 E-06$ WATT/CM**2

$9.945 \mathrm{E}-04$ WATT/CM**2

TIHE AVERAGED DISSIPATED POINER FROM FIHINIE $=5.405 E-06$

CELL NUMBER $=11$

1.379E-05

$3.493 E-05$

2.194E-04

$1.272 E-04$

HATT/CM**2

HATT/CH**2

HATT/CM**2

WATT/CN**2

HATT/CH**2

TIIIE AVERAGED DISSIPATED POWER FROH FINNIE=

$-8.912 E-05$

2. $120 \mathrm{E}-03$

TIME AVERAGED DISSIPATED POWER FROM FINHIE $=1.989 \mathrm{E}-05$

$1.612 E-05$

$3.468 \mathrm{E}-05$

$5.620 \mathrm{E}-05$

$4.484 E-04$

HATT/CM**2

WATT/CM**2

HATT/CM**2

HATT/CH**2

HATT/CH**2

HATT/CM**2

WATT/CM**2

$-8.344 \mathrm{E}-05$

$3.576 E-03$

TIHE AVERAGED DISSIPATED POWER FROH FINNIE $=4.525 \mathrm{E}-05$

2.281E-05

$4.622 \mathrm{E}-05$

$4.101 \mathrm{E}-05$

$1.041 E-03$

HATT/CH**2

HATT/CH**2

HATT/CH**2

HATT/CH* $* 2$

HATT/CH**2

HATT/CH**2

HATT/CM**2

$-2.130 E-05$

2.949E-03

$1.592 E-08$

HATT/CM**2

TINIE AVERAGED DISSIPATED POHER FROII FINIIIE=

$6.756 E-06$

$8.186 \mathrm{E}-06$

$1.045 \mathrm{E}-05$

$3.581 \mathrm{E}-07$

HATT/CH**2

WATT/CH**2

HATT/CM**2

WATT/CM**2

HATT/CH**2

WATT/CM\#*2 $\begin{array}{rl}-6.507 E-02 & M M / 1000 H \\ 1.218 E+02 & M M / 1000 H \\ 6.618 E-01 & M H / 1000 H \\ 1.689 E-01 & M M / 1000 H \\ 4.277 E-01 & H M / 1000 H \\ 2.687 E+00 & M M / 1000 H \\ 4.142 E-02 & M M / 1000 H\end{array}$

3.561E-01 MM/1000 H $1.550 \mathrm{E}+02 \mathrm{MH} / 1000 \mathrm{H}$ 2.089E-01 MH/1000 H

2.162E-01 MH/1000 H

6.660E-01 NN/1000 H

$2.935 \mathrm{E}+00 \mathrm{HM} / 1000 \mathrm{H}$

$1.210 \mathrm{E}-02 \mathrm{NM} / 1000 \mathrm{H}$ $\begin{array}{rl}-1.091 E+00 & M M / 1000 H \\ 2.596 E+02 & M H / 1000 H \\ 2.435 E+00 & M H / 1000 H \\ 1.974 E-01 & M H / 1000 \mathrm{H} \\ 4.246 \mathrm{E}-01 & \mathrm{HH} / 1000 \mathrm{H} \\ 6.882 \mathrm{H}-01 & M H / 1000 \mathrm{H} \\ 1.460 \mathrm{H}-01 & \mathrm{MM} / 1000 \mathrm{H}\end{array}$

$-1.022 E+00 \mathrm{MM} / 1000 \mathrm{H}$ $4.379 E+02 \mathrm{NM} / 1000 \mathrm{H}$

$5.541 \mathrm{E}+00 \mathrm{MM} / 1000 \mathrm{H}$

2.794E-01 MM/1000 H

$5.660 \mathrm{E}-01 \mathrm{HM} / 1000 \mathrm{H}$

$5.022 \mathrm{E}-01 \mathrm{HM} / 1000 \mathrm{H}$

3.389E-01 MH/1000 H $\begin{array}{rl}-2.608 E-01 & M M / 1000 \mathrm{H} \\ 3.611 E+02 & M M / 1000 \mathrm{H} \\ 1.950 E-03 & M M / 1000 \mathrm{H} \\ 8.273 E-02 & M M / 1000 \mathrm{H} \\ 1.002 E-01 & M M / 1000 \mathrm{H} \\ 1.279 E-01 & M H / 1000 \mathrm{H} \\ 1.166 E-04 & \mathrm{MH} / 1000 \mathrm{H}\end{array}$ 
TABLE 3 (cont'd)

300.

TIME-AVERAGED ENERGY DISSIP=

$-1.990 \mathrm{E}-05$ HATT/CM**2

$5.071 E-03$

301.

TIME-AVERAGED TOTAL KIHETIC ENERGY=

$1.906 \mathrm{E}-06$

TIME-AVERAGED HIEAN DIRECT RESIDUE=

$8.229 E-06$

303.

TIIE-AVERAGED CLOSED SOLUTIOH=

9.896E-06

TINE-AVERAGED RELATIVE VELOCITY MODEL=

$8.246 E-06$

305.

TIHE-AVERAGED NEILSON-GILCHRIST =

4.013E-05

WATT/CH**2

WATT/CH**2

HATT/CHA*2

WATT/CH $* 2$

HATT/CH**2

TIME AVERAGED ANGLE $=-4.107 \mathrm{E}-02$

HATT/CHA*2

307.

308.

309.

310.

311.

312.

313.

314.

315.

316.

317.

318.

319.

320.

321.

322.

CELL NUMBER $=16$

TIME-AVERAGED ENERGY DISSIP =

$-8.051 E-05$ WATT/CM**2

TIME-AVERAGED TOTAL KIHETIC ENERGY=

8.218E-03

TIME AVERAGED DISSIPATED POHER FROM FINNIE $=5.067 E-06$

TIHE-AVERAGED MEANI DIRECT RESIDUE=

$9.321 E-06$

TIIIE-AVERAGED CLOSED SOLUTION=

$1.166 E-05$

TIHE-AVERAGED RELATIVE VELOCITY MODEL=

9.337E-06

$1.066 E-04$

WATT/CM**2

WATT/CH**2

WATT/CM**2

TIIIE-AVERAGED NEILSON-GILCHRIST =

WATT/CH**2

TIME AVERAGED AHGLE $=-5.583 E-02$

WATT/CH**2

$-2.437 \mathrm{E}-09 \mathrm{NM} / 1000 \mathrm{H}$ $6.209 E+02 \mathrm{MH} / 1000 \mathrm{H}$

2.334E-01 MH/1000 II

1.008E-01 HMV/1000 H

$1.212 \mathrm{E}-01 \mathrm{MH} / 1000 \mathrm{HI}$

$1.010 \mathrm{E}-01 \mathrm{H} / 1000 \mathrm{H}$

$1.307 \mathrm{E}-02 \mathrm{HM} / 1000 \mathrm{H}$

HESSAGE SUIMMARY: MESSAGE MUMBER - COUNT

208 511 OR OVER

$-9.858 \mathrm{E}-01 \mathrm{MM} / 1000 \mathrm{H}$ $1.006 \mathrm{E}+03 \mathrm{NM} / 1000 \mathrm{H}$

$6.204 \mathrm{E}-01 \mathrm{MH} / 1000 \mathrm{H}$

$1.141 \mathrm{E}-01 \mathrm{HH} / 1000 \mathrm{H}$

$1.428 \mathrm{E}-01 \mathrm{MM} / 1000 \mathrm{H}$

$1.143 \mathrm{E}-01$ MMV $1000 \mathrm{H}$

3.471E-02 MII/1000 H. 
cell having a flag FL $=3$ (no slip or partial slip). The obstacle is clearly seen by the $2 \times 2$ array of flags $F L=3$ at lines 40 and 41 . The row of flags $F L=2$ represents the dummy cells along the line of symmetry. The indices of the flags go from $\mathrm{I}=1$ to $\mathrm{I}=33$ and $\mathrm{J}=1$ to $\mathrm{J}=14$ (not numbered). Thus, the cells counterclockwise around the obstacle (circled for clarity) in Table 3 are $(2,3),(3,3),(4,4),(4,5),(3,6)$, and $(2,6)$ and the corresponding surfaces are $K=1,2,4,6,8$, and 9 (also circled for clarity in Table 3). The row of cells $\mathrm{I}=32, \mathrm{~J}=2$ to 13 are the cells next to the solid (right) wall. The remaining surface numbers, $K=3,5$, etc., constitute the surface of the fluidized-bed side wall corresponding to the vertical row of flags $\mathrm{FL}=3$, for which erosion is also calculated. The CELL NUMBERS 1 through 16 correspond to $K=1$ through 16 in lines 47 though 63. For example, CELL NUMBER 1 corresponds to $I=2, J=3$, the lower surface of the obstacle next to the line of symmetry.

Table 4 shows the key for the time-averaged printed output for the first column of results representing the kinetic energy dissipated per unit volume $\mathrm{W} / \mathrm{cm}^{2}$ for each quantity indicated. The time dependent energy dissipation results are written to UNITS 51 through 56, as shown in Figure 4 in Section 5.2.

The corresponding time-averaged erosion results are given in the last column, starting at line 146 , in $\mathrm{mm} / 1,000 \mathrm{~h}$. These rates are for aluminum tube material having a hardness of 294 $\mathrm{MN} / \mathrm{m}^{2}\left(30 \mathrm{kgf} / \mathrm{mm}^{2}\right)$. The erosion rates for the MED ( $\left.\dot{\mathrm{EDVCF}}_{\mathrm{E}}\right)$, NG, and Finnie's erosion models are summarized in Figure 7 along with the impingement angles. The numbers at the bottom of each cell are the cell numbers from the printout given in Table 4.

A note of precaution is in order. It has been determined that if the FLUFIX standard problem 19 is run with the default convergence parameter, EPSG $=5 \times 10^{-4}$, slightly different hydrodynamic results are produced when using different computing platforms or compilers. This difference results in slightly different erosion rates and impingement angles. However, no such variable is encountered with the EROSION/MOD1 code run on different computer platforms. The computer platforms used were a B\&W SUN workstation, an ANL CRAY X-MP/18, and an IBM 3033 with Fortran 66 and Fortran 77 compilers. These results are available from the first author upon request.

The convention used to determine the sign of the angle, $\alpha$, is that the angle is negative if $\vec{v}_{s} \cdot \vec{n}>0$ and positive if $\vec{v}_{s} \cdot \vec{n}<0$. If the angle is negative, no erosion is computed in the NG, and Finnie erosion models (the solids flow away from the surface). This convention can be used to determine the direction of the velocity normal to a given surface from the printout of the timeaveraged impingement angles. 


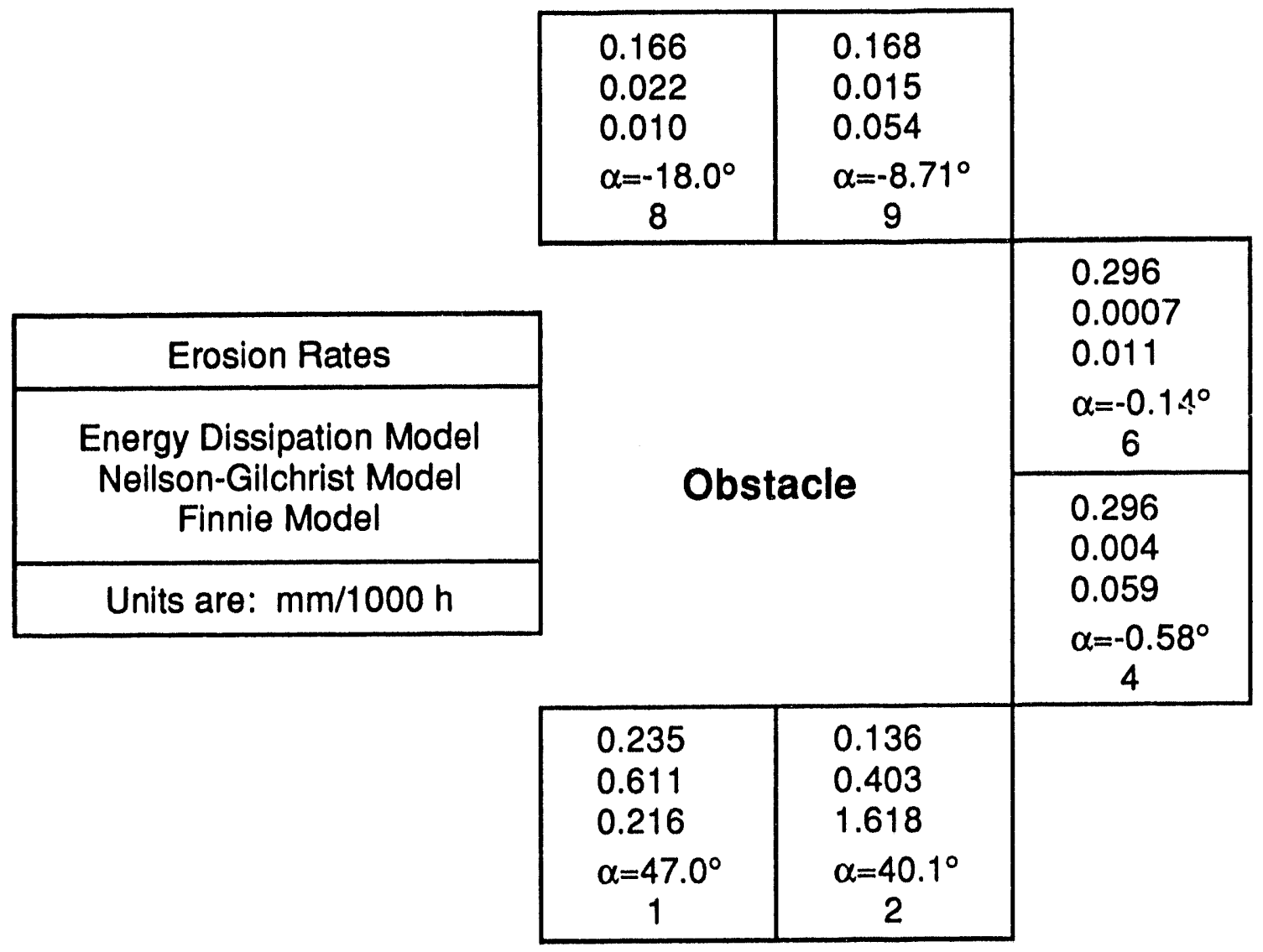

FIGURE 7 Summary of Computed Erosion Rates for the MED (E் EDvCF), NEILSON-GILCHRIST, and Finnie Erosion Models 
TABLE 4 Key for Energy Dissipation Printed Outputs

Variable

Energy Dissipation

Total Kinetic Energy

Dissipated Power from Finnie

Mean Direct Residue

Closed Solution

Relative Velocity Model

Nellson-Gilchrist

Angle

\section{Definition}

- UED

$=\left|\vec{v}_{\mathrm{s}}\right|^{2} / 2$

$=K_{E F} \quad=\dot{m}_{s}\left|\vec{v}_{s}\right|^{2} f(\alpha) / 8$

$=$ UEDV $=\left[\left(\varepsilon_{\mathrm{s}} \overline{\bar{\tau}}_{\mathrm{sv}}\right): \nabla \overrightarrow{\mathrm{v}}_{\mathrm{s}}\right] \mathrm{dp}$

$=$ UEDVCF $=\left[\left(\varepsilon_{s} \overline{\bar{\tau}}_{\mathrm{sv}}\right): \nabla \overrightarrow{\mathrm{v}}_{\mathrm{s}}+\overline{\bar{\beta}}_{\mathrm{B}} \mathrm{v}_{\mathrm{s}}{ }^{2} / 2\right] \mathrm{d}_{\mathrm{p}}$

Eq. 2.14b

Eq. $2.14 \mathrm{C}$

$=$ UEDVREL $=\left[\left(\varepsilon_{\mathrm{s}} \overline{\bar{\tau}}_{\mathrm{sv}}\right): \nabla \overrightarrow{\mathrm{v}}_{\mathrm{s}}+\varepsilon_{\mathrm{s}} \overline{\bar{\beta}}_{\mathrm{B}}\left(\overrightarrow{\mathrm{v}}_{\mathrm{g}}-\overrightarrow{\mathrm{v}}_{\mathrm{s}}\right)^{2}\right] \mathrm{d}_{\mathrm{p}} \quad$ Eq. $2.14 \mathrm{~d}$

$=$ KENG $=\left(\right.$ Eq. 2.6) $\times \xi_{\mathrm{b}}$

= Impingement Angle, $\alpha$, Degrees 


\section{Limitations of Current Erosion Models and Recommendations for Improvements}

It would not serve the reader well if the impression were left that the erosion models contained in the code EROSION/MOD1 had no limitations and could not be improved. In fact, quite a few uncertainties still exist, some of which have been alluded to at various points in this manual. The major limitations, assumptions, and recommendations for future improvements will now be discussed. ${ }^{3}$

1. The extension of the Finnie and NG erosion models that uses the mean mass flux may over predict erosion rates. Another approach recently developed that uses the kinetic theory of granular flow may be a more rational way to extend these models. 22

2. The factor $\mathbf{C}$ in Finnie's erosion model may be inappropriate for Tluidized beds. The value is taken from the original model to be $1 / 8$ and might be much lower for the nearly horizontal slow flow of particles near surfaces in fluidized beds.

3. The factor $P_{t}$ in Finnie's model is taken to be the Vickers hardness. It could be the yield strength, tensile strength, or any one of other hardnesses reported in the literature. This could easily produce a spread of one-half order of magnitude in predicted erosion rates.

4. As already discussed, the wear factors for the NG model are only for aluminum and are used at the lowest range of the experimental velocity data. Wear factors for other materials, and extension of them to low particle flows, are needed.

5. The particles in all the erosion models are assumed to not break up. This implies they are much harder than the eroding surface. It is known that the erosion rate decreases dramatically when the particles become less hard than the eroding surface. ${ }^{14}$ Clearly, the part of the kinetic energy dissipation going into attrition increases and predominates over the portion that causes erosion.

6. The MED erosion models depend upon an empirical restitution coefficient that is presently taken to be a reasonable value of $\mathrm{e}^{2}=0.9$, which could vary with impingement angle and velocity surface roughness and particle and eroding surface hardness. Raising $\mathrm{e}^{2}$ from 0.9 to 0.99 would lower the predicted MED erosion rates an order of magnitude.

7. The exact expression for the solids kinetic energy dissipation rate is not yet clear. We presently recommend Eq. 2.14b on the basis of the work of Bouillard and Lyczkowski. 17 We feel that the form given by Eq. $2.14 \mathrm{~d}$ is probably not correct. In short, the fraction of the energy dissipation caused by interphase drag that contributes to erosion is not a certainty.

8. There are two ways to evaluate $\varepsilon_{\mathrm{s}} \overline{\bar{\tau}}_{\mathrm{sv}}: \nabla \overrightarrow{\mathrm{v}}_{\mathrm{s}}$ one way uses cell-edge velocities and the other uses cell-centered velocities. These two means of evaluations render different results, with a variance of $20 \%$.

9. Only a single average particle size is used in the erosion models. The methodology should be extended to include at least two particle sizes, and a methodology should be developed to calculate the erosion due to each mass fraction of the particle size distribution.

In spite of the limitations enumerated above, reasonable predictions of erosion rates and patterns have, in our opinion, been produced that are on the correct order of magnitude if the 
solids hydrodynamics is correctly computed. Generally speaking, erosion rates are overpredicted at present and are hence conservative estimates. Items 1 through 9 should be reexamined in light of the present discussion. This is a major undertaking. 


\section{References}

1. Parkinson, M.J., J.F.G. Grainger, A.W. Jury, and T.J. Kempton, Tube Erosion at IEA Grimethorpe: Cold Model Studies at CRE-Appendix Ii in Tube Bank 'C'-Metal Wastage Status Report-August, 1983, Technical Report, NCB (IEA Grimethorpe) Ltd., Barnsley, South Yorkshore, United Kingdom (May 1984).

2. Finnie, I., Erosion of Surfaces by Solid Particles, Wear, 3:87-103 (1960)).

3. Neilson, J.H., and A. Gilchrist, Erosion by a Stream of Solid Particles, Wear, 11:111-122 (1968).

4. Yates, J.G., On Erosion of Metal Tubes in Fluidized Beds, Chem. Eng. Sci., 2:379-380 (1987).

5. Wood, R.T., and D.A. Woodford, Tube Erosion in Fluidized Beds, General Electric Co. Report 11/ET-FUC79, U.S. Energy Research and Development Administration Report 8112 (December 1980).

6. Gansley, R.F., and T.J. O'Brien, A Model for Bubble-Induced Erosion of Fluidized-Bed Combustors and Comparison With Experiment, Wear, 137:1(07-127 (1990).

7. Bouillard, J.X., R.W. Lyczkowski, S. Folga, D. Gidaspow, and G.F. Berry, Hydrodynamics of Erosion of Heat Exchanger Tubes in Fluidized Bed Combustors, Can. J. Chem. Eng., 67:908-922 (1989).

8. Lyczkowski, R.W., and J.X. Bouillard, Interim Users Manual for FLUFIXIMODI:A Computer Program for Fluid-Solids Hydrodynamics, Argonne National Laboratory Report ANL/EES-TM-361, Argonne, Ill. (February 1989).

9. Lyczkowski, R.W., J.X. Bouillard, D. Gidaspow, and G.F. Berry, Computer Modeling of Erosion in Fluidized Beds, Argonne National Laboratory Report ANL/ESD/TM-1, Argonne, Ill. (January 1990).

10. Bouillard, J.X., Hydrodynamics of Sedimentation, Fluidization and Erosion, Ph.D. Thesis, Illinois Institute of Technology, Chicago, Ill. (December 1986).

11. Pourahmadi, F., and J.A.C. Humphrey, Modeling Solid-Fluid Turbulent Flows with Application to Predicting Erosion Wear, Physico Chemical Hydrodynamics, 4(3):191-219 (1983).

12. Bitter, J.G.A., A Study of Erosion Phenomena, Part I, Wear, 6:5-21 (1963).

13. Bitter, J.G.A., A Study of Erosion Phenomena, Part II, Wear, 161-190 (1963).

14. Engel, P.A., Impact Wear of Materials, Elsevier Scientific Publishing Co., Amsterdam (1978).

15. Baumeister, T., Editor-in-Chief, Mark's Standard Handbook for Mechanical Engineers, 7th Ed., McGraw Hill, New York (1967). 
16. Ushimaru, K, C.T. Crowe, and S. Bernstein, Design and Applications of the Novel Slurry Jet Pump, Report No. E184-108, Technical Report, Energy International, Inc. (October 1984).

17. Bouillard, J.X., and R.W. Lyczkowski, On the Erosion of Heat-Exchanger Tube Banks in Fluidized-Bed Combustors, Powder Technology, 68:37-51 (1991).

18. Savage, S.B., Granular Flow at High Shear Rates, pages 339-357, Academic Press, New York (1982).

19. Lyczkowski, R.W., J.X. Bouillard, and S.M. Folga, Users Manual for FLUFIX/MOD2: A Computer Program for Fluid-Solids Hydrodynamics, Argonne National Laboratory Report, Argonne, Ill. (April 1992).

20. Rivard, W.C., and M.D. Torrey, KFIX: A Computer Program for Transient, TwoDimensional, Two-Fluid Flow, Los Alamos Scientific Laboratory Report LA-NUREG663 (April 1977).

21. Bouillard, J.X., R.W. Lyczkowski, and D. Gidaspow, Porosity Distributions in a FluidizedBed with an Immersed Obstacle, AIChE J., 35(6):908-922 (1989).

22. Ding, J., and R.W. Lyczkowski, Three-Dimensional Kinetic Theory Modeling of Hydrodynamics and Erosion in Fluidized Beds, Powder Technology, 73:127-138 (1992). 


\section{Appendix A: \\ Assessment of Nellson-Gllchrist Erosion Model}

A comparison of computed erosion rates in a fluidized bed for the Neilson-Gilchrist, erosion model was made with previously calculated erosion notes for Finnie's and the prototypical ${ }^{9}$ monolayer energy dissipation (MED) erosion models. The results are tabulated in Table A.1. The input values for all three models used were taken from the time-averaged hydrodynamic calculations previously performed.

Because of uncertainties in the extrapolated values from the empirical formulae for the ductile and brittle wear factors given by Eqs. 2.7 and 2.8 , to very much lower velocities typical of FBCs $(\sim 1 \mathrm{~m} / \mathrm{s})$, the erosion rates for the Neilson-Gilchrist erosion model were computed for three cases for which the velocity, $V$, were set to: (1) the magnitude of the time-averaged computed particle velocity, $\left|\vec{v}_{\mathrm{s}}\right|(\sim 1 \mathrm{~m} / \mathrm{s}) ;(2) 107.8 \mathrm{~m} / \mathrm{s}$ (the lower bound of the experimental particle velocity data); and (3) $200 \mathrm{~m} / \mathrm{s}$ (the upper bound of the experimental particle velocity data).

As can be seen in Table A.1, the Neilson-Gilchrist erosion rates with a velocity of $107.8 \mathrm{~m} / \mathrm{s}$ or $200 \mathrm{~m} / \mathrm{s}$ are about $1,(0)(0)$ times larger than those based on solids velocities calculated from the hydrodynamic model and are generally about the same as the early monolayer energy dissipation erosion model rates (except when they are zero). This is the reason for the recommendation to use the wear factors evaluated at $107.8 \mathrm{~m} / \mathrm{s}$, the lower bound of the experimental velocity data (Section 2.2). It is instructive to compare results in Table A.1 with those shown in Figure 7. 
TABLE A.1 Comparison of Erosion Models

\begin{tabular}{|c|c|c|c|c|c|}
\hline \multicolumn{6}{|c|}{ Erosion Range (mm/1,000 hrs) for Aluminuma } \\
\hline Locationb & $\begin{array}{c}V=\left|\vec{V}_{s}\right| \\
(\sim-1 \mathrm{~m} / \mathrm{s})\end{array}$ & $\begin{array}{l}\text { Ison and Gllchri } \\
V=107.8 \mathrm{~m} / \mathrm{s}\end{array}$ & $V=200 \mathrm{~m} / \mathrm{s}$ & Finnie & $\begin{array}{l}\text { Monolayer Energy } \\
\text { Dissipation } \\
\text { dp=500 } \mu \mathrm{m}\end{array}$ \\
\hline $\begin{array}{l}1 \\
2 \\
4 \\
6 \\
8 \\
9\end{array}$ & $\begin{array}{l}6.69 \times 10^{-4} \\
4.58 \times 10^{-4} \\
0.0 \\
0.0 \\
1.18 \times 10^{-4} \\
3.12 \times 10^{-3}\end{array}$ & $\begin{array}{l}0.172 \\
0.61 \\
0.0 \\
0.0 \\
0.30 \\
0.035\end{array}$ & $\begin{array}{l}3.82 \\
1.5 \\
0.0 \\
0.0 \\
0.68 \\
0.09\end{array}$ & $\begin{array}{l}0.216 \\
1.62 \\
0.06 \\
0.01 \\
0.01 \\
0.05\end{array}$ & $\begin{array}{l}0.235 \\
0.136 \\
0.296 \\
0.296 \\
0.166 \\
0.168\end{array}$ \\
\hline
\end{tabular}

a A hardness of $30 \mathrm{kgt} / \mathrm{mm}\left(294 \mathrm{MN} / \mathrm{m}^{2}\right)$ was used for the Finnie and Monolayer Energy Dissipation models.

b Refer to Figure 7 


\section{Appendix B: \\ EROSION/MOD1 Princlpal Fortran Symbols and Definitlons}

In the following list of Fortran symbols, the array quantities are indicated by an index. They are all part of a common block. The array dimensions of most of them need to be changed when the input data file is changed. The indexes shown in the following table and the respective array dimensions to be used are: $\mathrm{I} \rightarrow \mathrm{IB} 2$ and $\mathrm{IJ} \rightarrow \mathrm{IB} 2 \cdot \mathrm{JB} 2$ The rest are left unchanged unless otherwise specified.

Definition

BHITE Input date line No. 3

$\mathrm{C}(100) \quad$ Storage for constants initialized in SETC

DP $d p$, particle diameter, $\mathrm{cm}$, input data line No. $13+\mathrm{N}$

ERNG(K) Neilson-Gilchrist model energy dissipation, $W / \mathrm{m}^{2}$

$\operatorname{EROEF}(K) \quad$ Finnie model energy dissipation, $W / \mathrm{m}^{2}$

EROEF1(K) Total solids kinetic energy dissipation, $W / \mathrm{m}^{2}$

DX $\delta x$, read in line No. 3

DZ $\quad \delta z$, read in line No. 3

EPS The cutting wear factor, $\mathrm{J} / \mathrm{kg}$

EP1 Young's modulus of the solids, $\mathrm{Pa}$

ERNG Energy dissipation rate, erg $/ \mathrm{cm}^{2}$

ET1 Young's modulus of the target, $\mathrm{Pa}$

FL(IJ) Cell flags set up in FLIC

FLO(M) Input data line Nos. 5, 6, 7, and 9

HARD Eroding surface hardness, $\mathrm{kgf} / \mathrm{mm}^{2}$

I $\quad \mathrm{i}$, computing mesh column index

IB Number of cells in the radial direction, excluding the two fictitious columns; $\mathrm{IB}=\mathrm{IB} 2-2$

IB 1 IB $1=\mid \mathrm{B} 2-1$ 
IB2

IDRAG

IFLAG

IFR0, IFR1

IFR2, IFR3

IJ

IJB

IJBR

IJL

IJM

IJP

IJR

IJRR

IJT

IJTL

IJTR

IJTT

IMJ

IMJM

IPJ

IPJM

IPJP

IPRES

J

JB

JB1
Total number of cells in the radial direction, read in line No. 2

Read in line No. 2

Flag of erosion node (1:under, 2:right, 3:top, 4:left)

Dump control numbers read in line No. 1

Index of quantities for cell $(\mathrm{i}, \mathrm{j}) ; \mathrm{IJ}=\mathrm{I}+(\mathrm{J}-1) \cdot \mathrm{IB} 2$

Index of cell-centered quantities associated with cell $\mathrm{i}, \mathrm{j}-1$

Index of cell-centered quantities associated with cell $(i+1, j-1)$

Index of cell-centered quantities associated with cell $(i-1, j)$

Index of cell $(\mathrm{i}, \mathrm{j}-1)$

Index of cell $(I, j+1)$

Index of cell-centered quantities associated with cell $(i+1, j)$

Index of cell-centered quantities associated with cell $(i+2, j)$

Index of cell-centered quantities associated with cell, $(\mathrm{i}, \mathrm{j}+1)$

Index of cell-centered quantities associated with cell $(i-1, j+1)$

Index of cell-centered quantities associated with cell $(i+1, j+1)$

Index of cell-centered quantities associated with cell $(i, j+2)$

Index of cell $(i-1, j)$

Index of cell $(\mathrm{i}-1, \mathrm{j}-1)$

Index of cell $(i+1, j)$

Inde> of cell $(\mathrm{i}+1, \mathrm{j}-1)$

Index of cell $(i+1, j+1)$

Read in line No. 2

$\mathrm{j}$, computing mesh row index (z direction)

Number of cells in the axial direction, excluding the two fictitious rows $\mathrm{JB}=\mathrm{JB} 2-2$

$\mathrm{JB} 1=\mathrm{JB} 2-1$ 
JB2

Total number of cells in the axial direction, read in line No. 2

KDRAGX(IJ) $\quad r$ component of gas-solids friction

KDRAGY(IJ) $\quad \mathrm{z}$ component of gas-solids friction

KFLIN(K) Read in line No. 4

KFLOUT Read in line No. 7

MMUG Viscosity of gas used in the interphase drag, input data line No. $13+\mathrm{N}$

MUL Viscosity of solids used in viscous stress, input data line No. $12+\mathrm{N}$

NO Input data line No. 3

NSL(M) Input data line No. 10

$\mathrm{NSO}(\mathrm{M}) \quad$ Input data line No. $10+\mathrm{N}$

$\mathrm{OB}(\mathrm{M}, \mathrm{N}) \quad$ Input data line No. $10+\mathrm{N}$

$\mathrm{P}(\mathrm{IJ}) \quad$ Pressure in cell $(\mathrm{i}, \mathrm{j})$

PHI $\phi_{s}$, the shape factor, input data line No. $13+\mathrm{N}$

PHIN The deformation wear factor $(\mathrm{J} / \mathrm{Kg})$, energy dissipation, $\mathrm{W} / \mathrm{m}^{2}$

RES(K) Prototype energy dissipation model

RLO $\quad \rho_{\mathrm{s}}$, solids density, read in line No. $11+\mathrm{N}$

SIGMY The elastic load limit of target, $\mathrm{Pa}$

SLOPE Input data line No. $11+\mathrm{N}$

SP Poisson's ratio of the impinging solids

ST Poisson's ratio of the target

TAUV(K) The irreversible conversion to internal energy, $\mathrm{W} / \mathrm{m}^{2}$

TAUVCF(K) The closed form solution energy dissipation, $W / \mathrm{m}^{2}$

TAUVRL(K) The relative velocity energy dissipation, $\mathrm{W} / \mathrm{m}^{2}$

TH(IJ) $\quad\left(\varepsilon_{\mathrm{g}}\right)_{\mathrm{i}, \mathrm{j}}^{\mathrm{n+1}}$

THO Input data line No. $11+\mathrm{N}$

THZERO Input data line No. $11+\mathrm{N}$ 
UL(IJ)

$$
\left(\mathrm{U}_{\mathrm{s}}\right)_{i+\frac{1}{2}, \mathrm{j}}^{\mathrm{n}}
$$

VG(IJ)

$$
\left(V_{8}\right)_{i, j+\frac{1}{2}}^{n}
$$

VL(IJ)

$$
\left(V_{s}\right)_{i, j+\frac{1}{2}}^{n}
$$

$\mathrm{ZN} 1$

Unit normal vector on the obstacle (radial component)

ZN2

Unit normal vector on the obstacle (axial component)

ZT1

Unit tangential vector on the obstacle (radial component)

ZT2

Unit tangential vector on the obstacle (axial component) 


\section{Notice}

The EROSION/MOD1 computer program may be obtained from:

Energy Science and Technology Software Center

P. O. Box 1020

Oak Ridge, TN 37833

Telephone (615) 576-2606

FAX (615) 576-2865

E-Mail:ESTSC@ADONIS.OSTI.GOV 


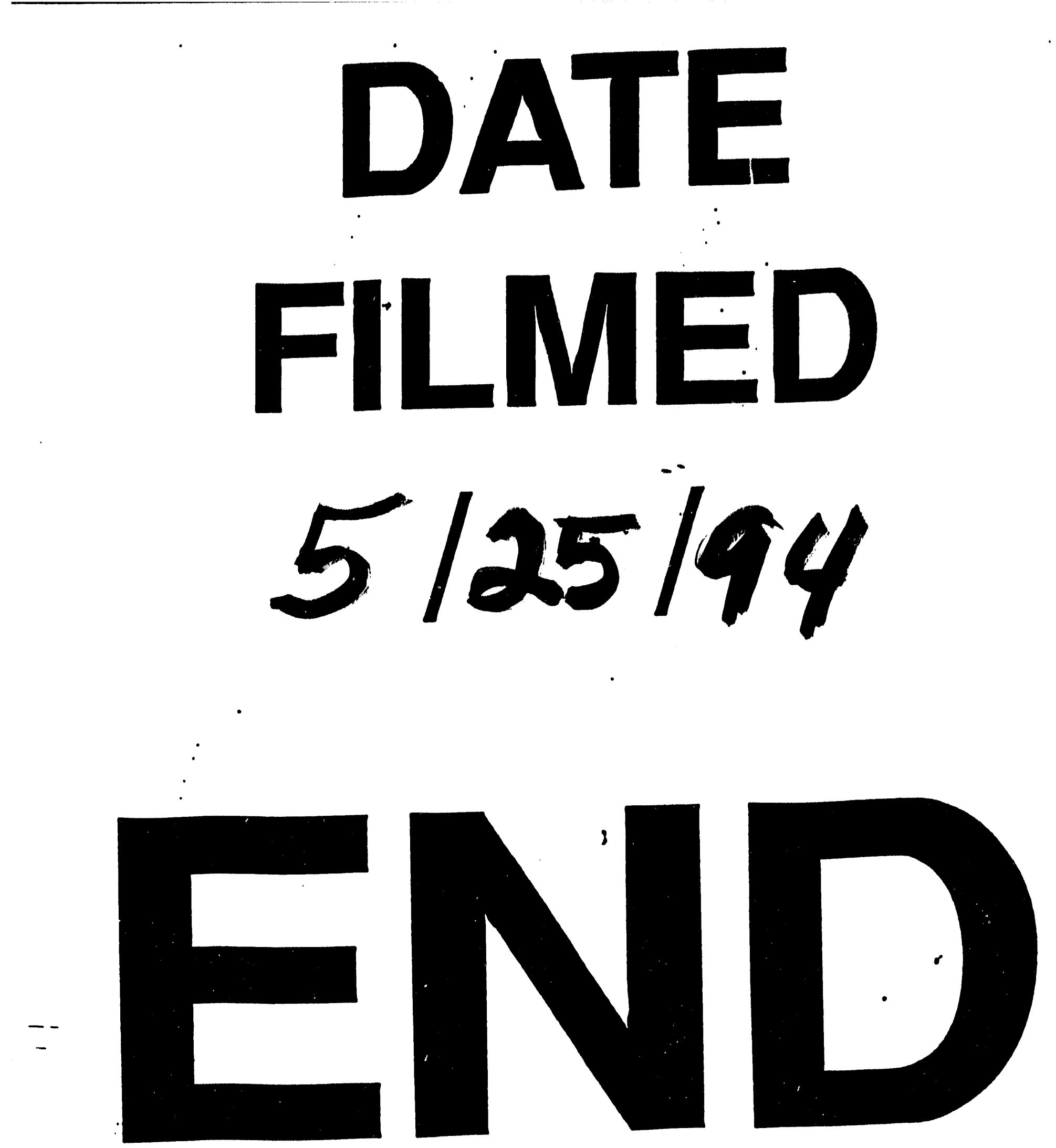




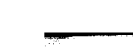
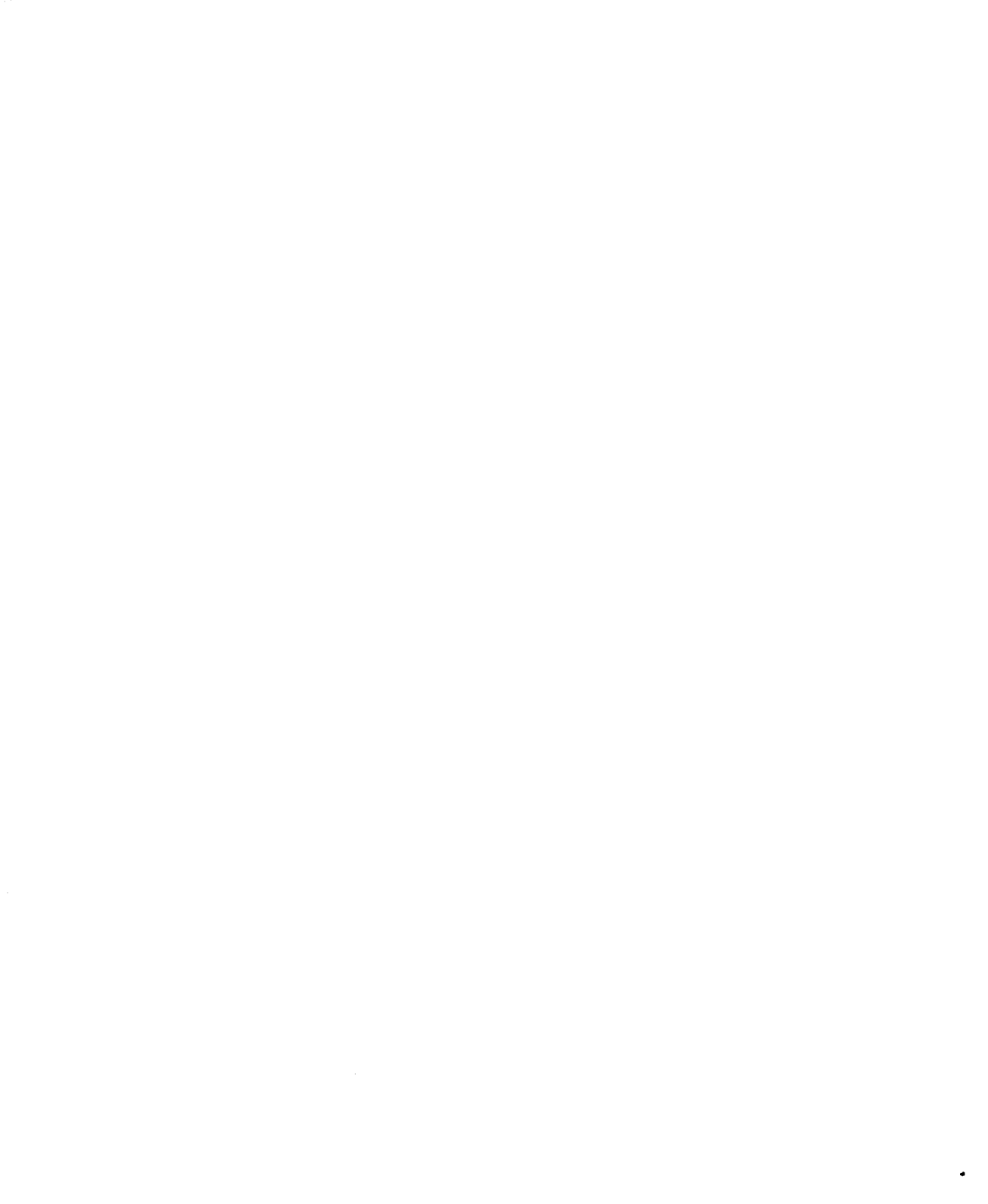